\title{
Effect of Metal Ions on Hybrid Graphite-Diamond Nanowire Growth: Conductivity Measurements from a Single Nanowire Device
}

\author{
Muthaiah Shellaiah ${ }^{1} \mathbb{D}$, Ying-Chou Chen ${ }^{2}$, Turibius Simon ${ }^{3}$, Liang-Chen $\mathrm{Li}^{4}{ }^{\mathbb{D}}$, \\ Kien Wen Sun ${ }^{1,2,4, *}$ and Fu-Hsiang Ko ${ }^{3}$ \\ 1 Department of Applied Chemistry, National Chiao Tung University, Hsinchu 300, Taiwan; \\ muthaiah1981@nctu.edu.tw \\ 2 Department of Electronics Engineering, National Chiao Tung University, Hsinchu 300, Taiwan; \\ biolab@faculty.nctu.edu.tw \\ 3 Department of Materials Science and Engineering, National Chiao Tung University, Hsinchu 300, Taiwan; \\ turibius.icn@gmail.com (T.S.); fhko@mail.nctu.edu.tw (F.-H.K.) \\ 4 Center for Nano Science and Technology, National Chiao Tung University, Hsinchu 300, Taiwan; \\ lcli@faculty.nctu.edu.tw \\ * Correspondence: kwsun@mail.nctu.edu.tw
}

Received: 14 February 2019; Accepted: 7 March 2019; Published: 11 March 2019

\begin{abstract}
Novel $\mathrm{Cd}^{2+}$ ions mediated reproducible hybrid graphite-diamond nanowire (G-DNWs; $\mathrm{Cd}^{2+}$-NDS1 NW) growth from 4-Amino-5-phenyl-4H-1,2,4-triazole-3-thiol (S1) functionalized diamond nanoparticles (NDS1) via supramolecular assembly is reported and demonstrated through TEM and AFM images. FTIR, EDX and XPS studies reveal the supramolecular coordination between functional units of NDS1 and $\mathrm{Cd}^{2+}$ ions towards NWs growth. Investigations of XPS, XRD and Raman data show the covering of graphite sheath over DNWs. Moreover, HR-TEM studies on $\mathrm{Cd}^{2+}$-NDS1 NW confirm the coexistence of less perfect $\mathrm{sp}^{2}$ graphite layer and $\mathrm{sp}^{3}$ diamond carbon along with impurity channels and flatten surface morphology. Possible mechanisms behind the G-DNWs growth are proposed and clarified. Subsequently, conductivity of the as-grown G-DNWs is determined through the fabrication of a single $\mathrm{Cd}^{2+}$-NDS1 NW device, in which the G-DNW portion L2 demonstrates a better conductivity of $2.31 \times 10^{-4} \mathrm{mS} / \mathrm{cm}$. In addition, we investigate the temperature-dependent carrier transport mechanisms and the corresponding activation energy in details. Finally, comparisons in electrical resistivities with other carbon-based materials are made to validate the importance of our conductivity measurements.
\end{abstract}

Keywords: nanodiamond; nanoparticles; metal ions induced graphitization; supramolecular assembly; graphite-diamond nanowires; carrier transport; carbon nanomaterials; conductivity; semiconductors

\section{Introduction}

Research on nanowires (NWs) growth has become essential due to its diverse applications [1-4]. For example, conducting or semiconducting NWs have been effectively applied in photonics or solar cells [5-7]. Therefore, much focus has been given for the construction of metallic or semiconducting NWs [8-10]. Development in hybrid semiconducting NWs has also become essential for diverse electrochemical and photonic applications [11-14]. For instance, research on hybrid graphite-diamond nanowires (G-DNWs) in electrochemical, sensing and semiconducting utilities are still intensive [15-18]. Moreover, these G-DNWs are employed in many novel nanoelectronic devices [19-21]. However, the effectiveness of these nanodevices is attributed to the insertion of graphene $\mathrm{sp}^{2}$ carbon over the 
surface of diamond $\mathrm{sp}^{3}$ carbon, which acts as an insulator [22,23]. The conductivity of the graphite sheath enfolding over the insulator diamond in G-DNWs can be improved by tuning the $\mathrm{sp}^{3} / \mathrm{sp}^{2}$ carbon ratio [24]. But, these G-DNWs are generally grown by means of chemical vapor deposition (CVD) techniques [25-28], which require costly instruments to sustain high temperature. Therefore, it is essential to find alternatives for the fabrication of the G-DNWs in a cost-effective way.

As reported earlier, self-assembled diamond nanoparticles (DNPs) tend to form graphite sheath over NW-like structure via electrostatic interactions [29-31]. Moreover, graphitization over DNPs can be enhanced by laser, dangling bonds, photon energy, metal ions and pHs [32-36]. These diamond/graphite $\left(\mathrm{sp}^{3} / \mathrm{Sp}^{2}\right)$ changes can be authenticated from Raman interrogations via in-plane bond stretching of $\mathrm{sp}^{2}$ graphite sheath represented by G-band coexisted with locally disordered forbidden D-band [37]. Moreover, doping of foreign substance, such as metal ions, may modify the $\mathrm{sp}^{3} / \mathrm{sp}^{2}$ ratios and lead to specific conductivity applications [38]. Recently, metal ion mediated self-assembly of DNPs that led to formation of hybrid G-DNW-like structure was reported $[39,40]$. In this way, ultrathin graphite-diamond nanorods with $2.1 \mathrm{~nm}$ diameter were fabricated from diamond clusters through self-assembly using microwave plasma chemical vapor deposition (MPCVD) technique and then applied in field emission studies [41]. In contrast, our group recently reported a cost-effective wet chemical route for the construction of G-DNWs via $\mathrm{pH}$ induced self-assembly of cysteamine functionalized DNPs (ND-Cys) [36]. In a similar fashion, a metal ion mediated self-assembly of ND-Cys DNPs are delivered to provide the G-DNWs-like structure [42] which allow us to continue the perfection of such G-DNWs.

To further improve the conducting nature of DNWs, the graphite sheath enfolding is enhanced by doping of $\mathrm{S}$ and $\mathrm{N}$ atoms over the surface. The presence of $\mathrm{S}$ and $\mathrm{N}$ atoms effectively increased the adsorption of metal ions with specific coordination as reported earlier by our group [42]. In this light, the presence of aromatic phenyl group was able to improve the conductivity via participation of its inner electronic conjugation. Hence, to expand the uniqueness and electrical conduction of formed G-DNWs, the DNPs were firstly functionalized by 4-Amino-5-phenyl-4H-1,2,4-triazole-3-thiol (S1, containing phenyl group, $\mathrm{S}$ and $\mathrm{N}$ atoms) via profitable wet chemical route to provide the NDS1. With the presence of phenyl unit, $\mathrm{S}$ and $\mathrm{N}$ atoms, metal ions are coordinated with certain extend to form the graphite-wrapped NW-like assemblies. However, only certain metal ions with the NDS1 may form the G-DNWs with good reproducibility. For example, $\mathrm{Cd}^{2+}$ ions form the G-DNWs $\left(\mathrm{Cd}^{2+}-\mathrm{NDS1} \mathrm{NWs}\right)$ at higher percentile with great reproducibility and smooth morphology than other ions. Similar to the fabrication of single $\mathrm{Sb}_{2} \mathrm{Se}_{3} \mathrm{NW}$ [43], poly(3-hexylthiophene) NW [44] and G-DNW [36] towards thermoelectric or conductivity studies, a single $\mathrm{Cd}^{2+}-\mathrm{NDS1} \mathrm{NW}$ device is successfully fabricated and the conductivity and electron transport properties are investigated in this work.

Herein, we report the $\mathrm{Cd}^{2+}$ induced self-assembly of novel 4-Amino-5-phenyl-4H-1,2,4-triazole-3-thiol (S1) functionalized diamond nanoparticles (NDS1) which lead to the G-DNWs $\left(\mathrm{Cd}^{2+}\right.$-NDS1 NWs) growth. The conductivity and electron transport mechanisms of the as-grown $\mathrm{Cd}^{2+}-\mathrm{NDS} 1 \mathrm{NWs}$ are well demonstrated by a single $\mathrm{Cd}^{2+}$-NDS1 NW device.

\section{Materials and Methods}

\subsection{General Information}

Commercial nanodiamond powder (DNPs) with a size of 4-12 $\mathrm{nm}$ was purchased from BAOO-WEI INTERNATIONAL CO., LTD., Taichung, Taiwan. 4-Amino-5-phenyl-4H-1,2,4-triazole-3-thiol (S1) and Thionyl chloride $\left(\mathrm{SOCl}_{2}\right)$ were obtained from Sigma Aldrich (Taiwan Merck Co., Ltd, Taipei, Taiwan). Anhydrous reactions were completed under nitrogen atmosphere by following the standard procedures. Appropriate drying agents were utilized in the distillation of solvents. Fourier transform Infrared spectroscopy (FTIR), Raman spectroscopy, scanning electron microscopy (SEM), transmission electron microscopy (TEM), zeta 
potential, energy dispersive spectrum (EDX) and X-ray photoelectron spectroscopy (XPS) were employed to identify and characterize the as-synthesized nanodiamond derivatives (NDS1). SEM and EDX measurements were done by JEOL-JSM-6700 (JEOL Ltd., Tokyo, Japan). TEM and HR-TEM data were attained by JEOL-JEM-2100 and JEOL-JEM-2100F (JEOL Ltd., Tokyo, Japan), respectively. AFM data were taken in a tapping mode using a Digital Instrument model atomic force microscope (AFM D3100; EXW Charlotte, NC, USA). The size of NDS1 NPs and its zeta potential were obtained from SEM, TEM and dynamic light scattering BECKMAN COULTER Delsa ${ }^{\text {TM }}$ Nano C particle analyzer (Beckman Coulter Inc., Brea, CA, USA). FTIR investigations were carried out by Perkin Elmer 100 FT-IR SPECTRUM ONE spectrometer (PerkinElmer Inc., Waltham, MA, USA). Raman interrogations were done with a combination of HOROBA (HORIBA FRANCE SAS, Palaiseau France), Lab RAM HR instrumental set up and a $488 \mathrm{~nm}$ solid state laser. The powder XRD data of p-ND, NDA and NDS1 were achieved from BRUKER AXS D2 Phaser (a26-x1-A2BOE2B; Bruker AXS Inc., Madison, WI, USA). XPS measurements were performed by a Microlab-350 (Thermo Electron Corporation; Waltham, MA, USA). The synthetic procedures for NDS1 and details on data collections of SEM, TEM, DLS, XPS, XRD, AFM, FTIR, Raman, calculations of reproducibility and stability of G-DNWs growth are provided in supporting information.

Following instruments were employed in the fabrication of single $\mathrm{Cd}^{2+}$-NDS1 NW fabrication. The Oxford Instruments Plasmalab80Plus was employed for plasma-enhanced chemical vapor deposition of a $300 \mathrm{~nm} \mathrm{SiO}$ layer over an N-type Si substrate. Next, double-side mask aligner (model: AG1000-4D-D-S-M-V; M\&R Nano Technology co. Ltd, Taoyuan, Taiwan) was used in the electrode design. Subsequently, alignment marks and completion of electrodes interconnections were done using an electron beam lithography system (ELS-7500EX; ELIONIX INC., Tokyo, Japan). Dual-Beam focus ion beam microscope (FIB) (model: LYRA3; TESCAN, Brno - Kohoutovice, Czech Republic) was utilized to allocate the $\mathrm{Cd}^{2+}-\mathrm{NDS1} \mathrm{NW}$ and to make electrical contact. The deposition of Ti/Au electrode contacts was done by a thermal evaporator TE-400. Finally, the electrical conductivity and temperature-dependent conductivity measurements from the metal-oxide-semiconductor field-effect transistor (MOSFET) structures were obtained from a cryogenic probe station (CG-196-Model; Everbeing Int'l Corp., Hsinchu, Taiwan) and a semiconductor device parameter analyzer (Keysight B1500; KEYSIGHT TECHNOLOGIES, Taipei, Taiwan).

\subsection{Fabrication of a Single $C d^{2+}-N D S 1 N W$}

Allocation of a single $\mathrm{Cd}^{2+}$-NDS1 NW was carried out by selecting a successfully grown nanowire

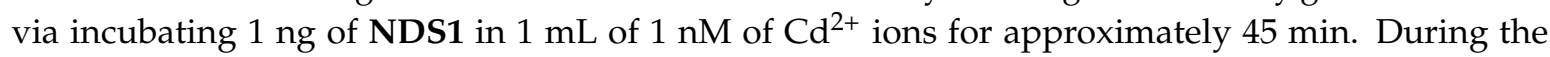
allocating processes of a single $\mathrm{Cd}^{2+}$-NDS1 NW, the cleaning process in each step was done by ultrasonication with Acetone, IPA and DI water followed by $\mathrm{N}_{2}$ purging to remove water. The steps for allocating a single $\mathrm{Cd}^{2+}$-NDS1 NW are descripted as follows: (1) Selection of a heavily doped N-type silicon wafer as a substrate; (2) The selected Si-wafer was treated with $\mathrm{H}_{2} \mathrm{SO}_{4}: \mathrm{H}_{2} \mathrm{O}_{2}=3: 1$ for 10 min to oxidize the organic materials on the surface and then washed by DI-water; The Si-wafer was further exposed to diluted HF to remove the oxide present on the surface; (3) Deposition of $\mathrm{SiO}_{2}$ (300 nm) on the Si-substrate by PECVD (model: plasmalab 80 plus; Oxford Instruments, Concord, MA, USA; at $300{ }^{\circ} \mathrm{C}$, RF plasma: $25 \mathrm{~W}$, Chamber pressure: $1000 \mathrm{mTorr}, \mathrm{SiH}$ 4:9 sccm, N $\mathrm{O}_{2} 710 \mathrm{sccm}$, reaction time: $250 \mathrm{~s}$ ); (4) Completion of outside pad (Figure S21 in supporting information) via cleaning process, spin coating of hexamethyldisilazane (HMDS) and photoresist, UV lithography, thermal evaporation of $20 \mathrm{~nm} \mathrm{Ti}$ and $60 \mathrm{~nm} \mathrm{Au}$, followed by lift off in acetone for more than 1 day. The completed 4-inch wafer was then cut into $2.2 \mathrm{~cm}$ pieces; (5) Completion of alignment mark (Figure S22 in supporting information) through cleaning process, spin coating the photoresist, E-beam lithography followed by thermal evaporation of Ti/Au (20/60 nm) and then lift off; (6) Deposition of dispersed $\mathrm{Cd}^{2+}-\mathrm{NDS1} \mathrm{NWs}$ at $1 \mathrm{ng} / \mathrm{mL}$ of water; (7) SEM observation of the NW distributions; (8) Utilization of FIB to fix the single $\mathrm{Cd}^{2+}$-NDS1 NW as well as making electrical contact; (9) Completion of electrode connections by means of cleaning process, spin coating the photoresist, E-beam lithography followed 
by thermal evaporation of $\mathrm{Ti} / \mathrm{Au}(20 / 100 \mathrm{~nm})$ and finally lift off. The above fabricated device was used in current-voltage (I-V), temperature-dependent conductivity and MOSFET measurements.

\subsection{Activation Energy $\left(E_{a}\right)$ Calculations}

The activation energy [45] of diamond NW portion L2 was calculated by the following Equation:

$$
\mathrm{R}=\mathrm{R}_{0} \exp ^{(\mathrm{Ea} / \mathrm{kT})}
$$

where $\mathrm{R}$ and $\mathrm{R}_{0}$ are the resistance of $\mathrm{L} 2$ with and without applied voltage, respectively, $\mathrm{k}$ is the Boltzmann constant and $\mathrm{T}$ is temperature in kelvin (K). By plotting the $\ln R$ as a function of $1 / \mathrm{T}$ (Figure S27 in supporting information), the activation energy $\left(\mathrm{E}_{\mathrm{a}}\right)$ can be determined from the slope of the curve.

\subsection{Evaluation of Electron Transport Mechanisms}

To determine the electron transport mechanisms [46] involved in the C $\mathrm{d}^{2+}$-NDS1 NW (L2 portion), conductivity and $\ln R$ were plotted as a function $1 / \mathrm{T}$ and $\mathrm{T}^{-1 / 4}$, respectively, where $\mathrm{R}$ stands for electrical resistance and $\mathrm{T}$ represents the temperature. Both curves were fitted linearly and nonlinearly. Similarly, $\ln \sigma$ was plotted as a function of $\mathrm{T}^{-1 / 4}$, which was then used to derive the relation of $\mathrm{E}$ as a function of $\mathrm{T}$, where $\sigma$ represents the conductivity (for our case obtained $\sigma_{0}=0.0077$ ) and $\mathrm{E}$ stands for energy. The relation of E versus T can be fitted with Mott's 3D hopping energy and thermal energy, which can be obtained from the following Equation:

$$
\mathrm{W}_{\mathrm{VRH}}=\frac{1}{4} \mathrm{KT}\left(\mathrm{T}_{\mathrm{M}} / \mathrm{T}\right)^{1 / \mathrm{d}+1}
$$

where VRH stands for variable range hopping, $\mathrm{kT}$ is known as thermal energy, $\mathrm{T}$ represents temperature and $T_{M}$ is described as Mott's characteristic temperature (in this case $T_{M}=60603 \mathrm{~K}$ ). The plot of $\ln \sigma$ $V s \mathrm{~T}^{-1 / 4}$ at temperature of $200-80 \mathrm{~K}$ can be fitted with three-dimensional (3D) Mott variable range hopping model (with $\mathrm{d}=3$ in Equation (2)).

\section{Results and Discussions}

As shown in Figure S1 in supporting information, slightly modified synthetic route [36,47] was followed to obtain NDS1 from pristine nanodiamond (p-ND) particles. In which the synthesized ND-Acidchloride (NDA) was directly refluxed with excess 4-Amino-5-phenyl-4H-1,2,4-triazole-3-thiol (S1) to produce the NDS1. During synthesis, intermediates and NDS1 were obtained with considerable yields. The equilibrium states of S1 (Figure S2 in supporting information) may avoid the competitive reactions of acid chloride with sulfur group, which equilibrate as free thiol (-SH) or thione (=S). Hence, these ND-Acidchloride can easily react with free primary amine $\left(-\mathrm{NH}_{2}\right)$ group to form the stable NDS1 structure as shown in Figure 1. 


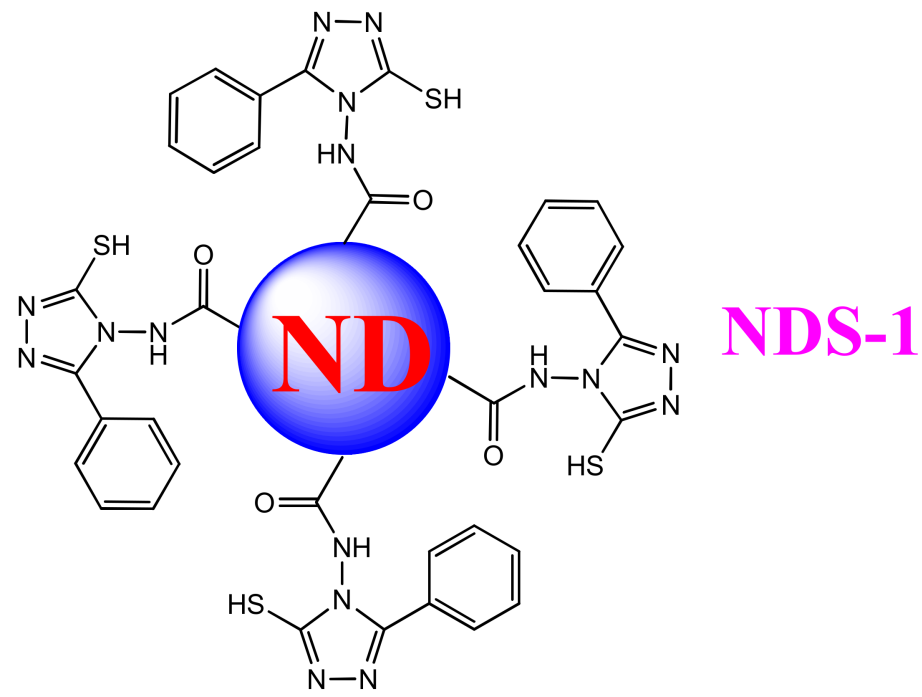

Figure 1. Model structure of NDS1 obtained from pristine nanodiamond ( $\mathrm{p}-\mathrm{ND}$ ) particles.

The as-synthesized NDS1 was characterized by FTIR and Raman spectroscopy. As shown in Figure S3 in supporting information, $-\mathrm{C}=\mathrm{O}$ stretching of NDS1 is presented at $1695 \mathrm{~cm}^{-1}$, together with p-ND (at $1643 \mathrm{~cm}^{-1}$ ) and NDA (at $1601 \mathrm{~cm}^{-1}$ ). Moreover, the stretching of $-\mathrm{OH}$ and $-\mathrm{COOH}$ from p-ND and NDA occur at 3413 and $3396 \mathrm{~cm}^{-1}$, respectively. However, the amide $-\mathrm{NH}$ from the NDS1 is broadened from 3032 to $3400 \mathrm{~cm}^{-1}$. The aromatic $-\mathrm{CH}$ stretching of NDS1 occurs at 2868 $\mathrm{cm}^{-1}$. Note that the free thiol (-SH) and amide -NH asymmetric bands of NDS1 appear at 2562 and $1475 \mathrm{~cm}^{-1}$, respectively. On the other hand, free thiol (-SH) of S1 is revealed at $2574 \mathrm{~cm}^{-1}$. The $-\mathrm{NH}$ bending stretch of NDS1 appears at $1561 \mathrm{~cm}^{-1}$ in contrast to $\mathbf{S 1}\left(-\mathrm{NH}\right.$ bending at $\left.1529 \mathrm{~cm}^{-1}\right)$. Other than the FTIR measurements, Raman interrogations also confirmed the formation of NDS1. As shown in Figure S4 in supporting information, D and G bands of p-ND and NDA appear at 1323 and 1605 $\mathrm{cm}^{-1}$, respectively. However, for NDS1, the D and G bands occur at 1374 and $1585 \mathrm{~cm}^{-1}$, respectively, wherein the intensity of the $\mathrm{G}$ band also demonstrates the occurrence of partial graphitization. The $-\mathrm{COOH}$ and amide -NH bands of NDA and NDS1 are broadened from 3200 to $3600 \mathrm{~cm}^{-1}$. In a similar fashion, zeta potential of NDS1 (Figure S5 in supporting information) further confirms the functionalization of $\mathbf{S} 1$ over the nanodiamond surface. In contrast to the p-ND $(-25.29 \mathrm{mV})$ and NDA $(-27.94 \mathrm{mV})$, the NDS1 possesses a positive zeta potential $(+8.66 \mathrm{mV})$.

To further confirm the functionalization of $\mathbf{S 1}$, the elemental investigations were done by EDX and XPS. As illustrated in Figure S7 in supporting information and Table 1, the existence of S $(5.47 \%)$ and $\mathrm{N}(17.71 \%)$ atoms with increased $\mathrm{O}(17.40 \%)$ and reduced $\mathrm{C}(59.42 \%)$ atomic concentrations proves that the $\mathbf{S 1}$ is capped over ND surface. Likewise, the presence of these atoms is validated from the XPS of NDS1 [Figure 2, Figure S8a-d and Table S1 in supporting information]. C1s peaks at 284.5 and 286.2 $\mathrm{eV}$ in the XPS spectra of $\mathrm{C}$ atom also imply the occurrence of partial graphitization. On the contrary, the manifestation N, O and S atoms are found by the N1s, O1s and S2p peaks at 401.5, 533.7 and 164.5 $\mathrm{eV}$, respectively. Next, the morphology and particle sizes of the NDS1 were investigated via SEM, TEM, AFM and DLS. As shown in Figure 3a, SEM image of NDS1 reveals the diverse morphology than that of p-ND and NDA. Moreover, the particle size of NDS1 at $100 \mu \mathrm{g} / \mathrm{mL}$ in water is $125.4 \pm 76.9$ $\mathrm{nm}$ as determined by dynamic light scattering (DLS) analysis (Figure S6 in supporting information). However, at much lower dispersed concentrations [48,49] (such as $1 \mathrm{ng} / \mathrm{mL}$ in water), DLS-based calculations become less effective. Therefore, TEM and AFM were used instead to determine particle sizes, as described in the following sections. 
Table 1. EDX data of ND derivatives and $\mathrm{Cd}^{2+}-\mathrm{NDS1}$ NWs.

\begin{tabular}{cccccc}
\hline Compound & $\mathbf{C ~ ( \% )}$ & $\mathbf{O}(\%)$ & $\mathbf{N}(\%)$ & $\mathbf{S ~ ( \% )}$ & $\mathbf{C d ~ ( \% )}$ \\
\hline p-ND & 96.21 & 3.79 & - & - & - \\
NDA & 87.32 & 12.68 & - & - & - \\
NDS1 & 59.42 & 17.40 & 17.71 & 5.47 & - \\
Cd $^{2+}$-NDS1 & 51.60 & 16.51 & 14.46 & 5.22 & 12.21 \\
NWs & & & & & \\
\hline
\end{tabular}

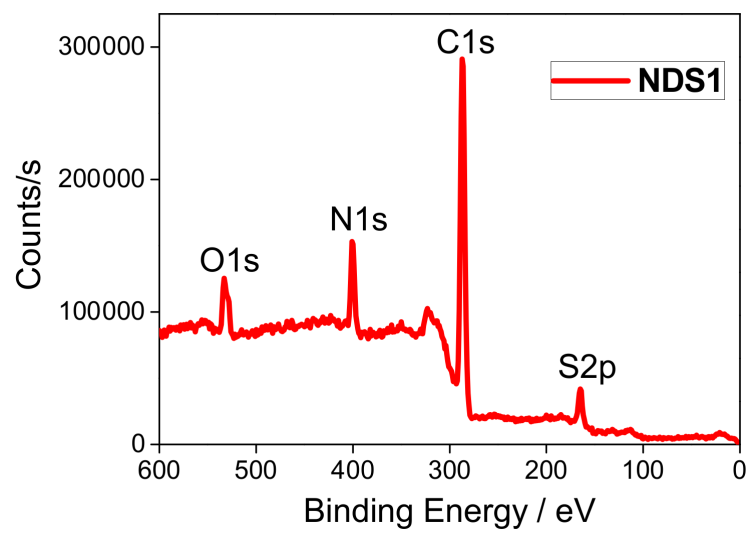

Figure 2. XPS spectrum of NDS1 confirms the presence of Carbon (C1s), Nitrogen (N1s), Oxygen (O1s) and Sulfur (S2p) atoms.

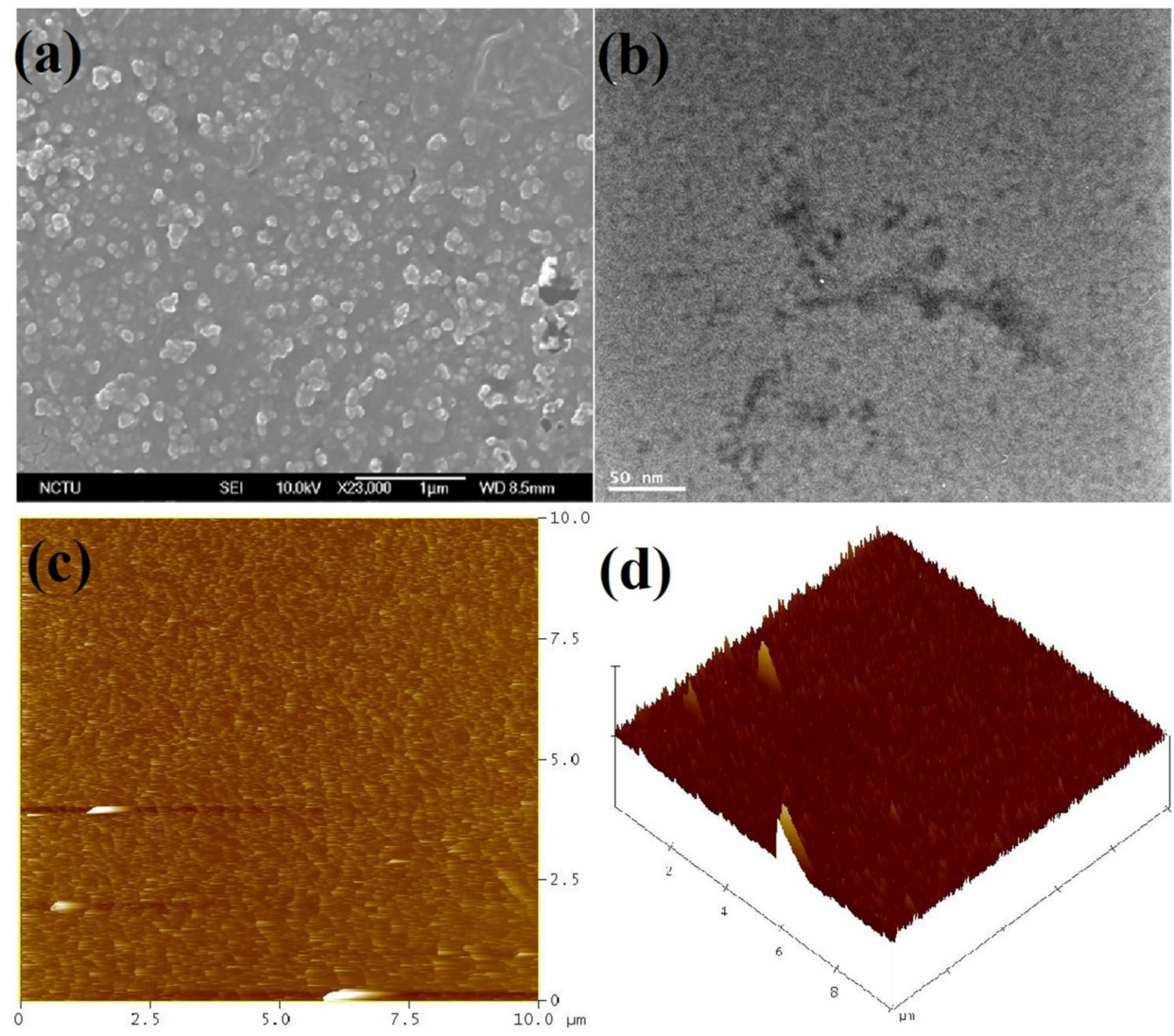

Figure 3. (a) Scanning electron microscopy (SEM) image of NDS1 at $100 \mu \mathrm{g} / \mathrm{mL}$ dispersion (scale: $1 \mu \mathrm{m}$ ); (b) Transmission electron microscopy (TEM) image of NDS1 at $1 \mathrm{ng} / \mathrm{mL}$ dispersion (scale: $50 \mathrm{~nm}$ ); (c) Atomic force microscopy (AFM) image of NDS1 at $10 \mu \mathrm{g} / \mathrm{mL}$ dispersion (scan range: 0-10 $\mu \mathrm{m}$ ) and (d) AFM height image of NDS1 at $10 \mu \mathrm{g} / \mathrm{mL}$ dispersion (scan range: $0-10 \mu \mathrm{m}$ ). 
TEM interrogation of NDS1 at $1 \mathrm{ng} / \mathrm{mL}$ in water is displayed in Figure $3 \mathrm{~b}$, which confirms the existence of smaller size particles. As noted in Figure 3c,d, the AFM images of surface and height also confirm the small particles along with large particles. HR-TEM image shown in Figure 4a at 1 $\mathrm{ng} / \mathrm{mL}$ in water confirms the presence of smaller NDS1 agglomerated particles. Hence, we conclude that the particle size of NDS1 must lies between 15 200 nm. The HR-TEM studies further prove the partial graphitization of nanodiamond occurred during functionalization of $\mathbf{S 1}$ via the images of amorphous graphite along with the diffraction pattern of nanodiamonds. Figure $4 \mathrm{~b}$ and the inset show the nanodiamond (111) diffraction distance of $0.206 \mathrm{~nm}$ and the amorphous graphite enfoldment [50]. In the HR-TEM analysis, the existence of defects or impurity channels may arise from the wet chemical synthesis of DNPs, which leads to the formation of less perfect $\mathrm{sp}^{2}$ graphite layer over DNWs. This issue will be discussed latter. The crystallinity of NDS1 is authenticated by powder XRD analysis as displayed in Figure S9 in supporting information. The NDS1 shows XRD peaks at $2 \theta=43.59,75.24$ and 91.46 corresponding to the (111), (220) and (311) diffraction patterns of nanodiamonds, respectively. Moreover, a mild amorphous graphite peak can be seen at $2 \theta=25.5$, which is attributed to the partial graphitization of NDS1 during the experiment.

The development of graphitized hybrid G-DNWs was done by incubating $100 \mu \mathrm{g}$ of NDS1 with $100 \mu \mathrm{M}$ of cations $\mathrm{Na}^{+}, \mathrm{Ni}^{2+}, \mathrm{Fe}^{3+}, \mathrm{Cd}^{2+}, \mathrm{Ca}^{2+}, \mathrm{Ga}^{3+}, \mathrm{Cr}^{3+}, \mathrm{Cu}^{2+}, \mathrm{Fe}^{2+}, \mathrm{Mg}^{2+}, \mathrm{Au}^{3+}, \mathrm{Y}^{3+}, \mathrm{Al}^{3+}, \mathrm{Ag}^{+}$, $\mathrm{Co}^{2+}, \mathrm{Zn}^{2+}, \mathrm{Pb}^{2+}, \mathrm{Mn}^{2+}$ and $\left.\mathrm{Hg}^{2+}\right)$ in $1 \mathrm{~mL}$ of water for $45 \mathrm{~min}$ as detailed in supporting information. As shown in Figures S10 and S11 in supporting information, majority of the cations tend to form the NWs via metal ion mediated self-assembly of NDS1. However, in order to successfully conduct conductivity studies, highly reproducible NW (NDS1 NW) formation is evaluated as discussed in supporting information. From 100 collected data of G-DNWs with different metal ions, we concluded that NDS1 NWs grown in the presence of $\mathrm{Cd}^{2+}$ ions showed $24 \%$ reproducibility (as shown in Figure 5), which was the highest among all ions. Above reproducibility can be further improved to $36 \%$ upon incubating the NDS1 with $\mathrm{Cd}^{2+}$ ions for $24 \mathrm{~h}$. However, further reproducibility enhancement beyond $36 \%$ cannot be achieved. As shown in the SEM images [Figs. $6 \mathrm{a}$ and $6 \mathrm{~b}$ and S12 in supporting information], diverse $\mathrm{Cd}^{2+}$-NDS1 NWs are formed at $10 \mu \mathrm{g}$ of NDS1 with $10 \mu \mathrm{M}$ of $\mathrm{Cd}^{2+}$ ions per $\mathrm{mL}$ in water. On the other hand, at higher dispersive concentrations, such as 100 picogram (pg) of NDS1 with 100 picomolar (pM) of $\mathrm{Cd}^{2+}$ ions, NW formation cannot be observed. Variations of either NDS1 or $\mathrm{Cd}^{2+}$ have led to the agglomeration of particles.

The formed G-DNWs $\left(\mathrm{Cd}^{2+}\right.$-NDS1 NWs) were well characterized as described next. The width of $\mathrm{Cd}^{2+}$-NDS1 NWs are between 50 to $980 \mathrm{~nm}$ with average lengths of $100 \mathrm{~nm} \sim$ hundreds of microns, depending on the dispersion concentrations which can be adjusted from $1 \mathrm{ng} \sim 100 \mu \mathrm{g}$ of NDS1 with $1 \mathrm{nM} \sim 100 \mu \mathrm{M}$ of $\mathrm{Cd}^{2+}$ ions, correspondingly. Due to the multi-dispersive nature of NDS1 with $\mathrm{Cd}^{2+}$ ions, longer G-DNWs are formed with larger diameters than those of earlier reports on diamond NWs with 5-20 nm in diameter [51]. However, with the variations in dispersion concentrations of NDS1 from $100 \mu \mathrm{g}$ to $1 \mathrm{ng}$ and $\mathrm{Cd}^{2+}$ ions from $100 \mu \mathrm{M}$ to $1 \mathrm{nM}$, respectively, the supramolecular self-assembled and scattered $\mathrm{Cd}^{2+}$-NDS1 NWs with limited difference in lengths and diameters are formed, as shown in the TEM images [Figure $6 c, d$ and Figure S13 in supporting information]. When the dispersion of NDS1 and concentrations of $\mathrm{Cd}^{2+}$ ions were further diluted, the $\mathrm{Cd}^{2+}$-NDS1 NWs formation can be affected due to lack of supramolecular interactions between them. 

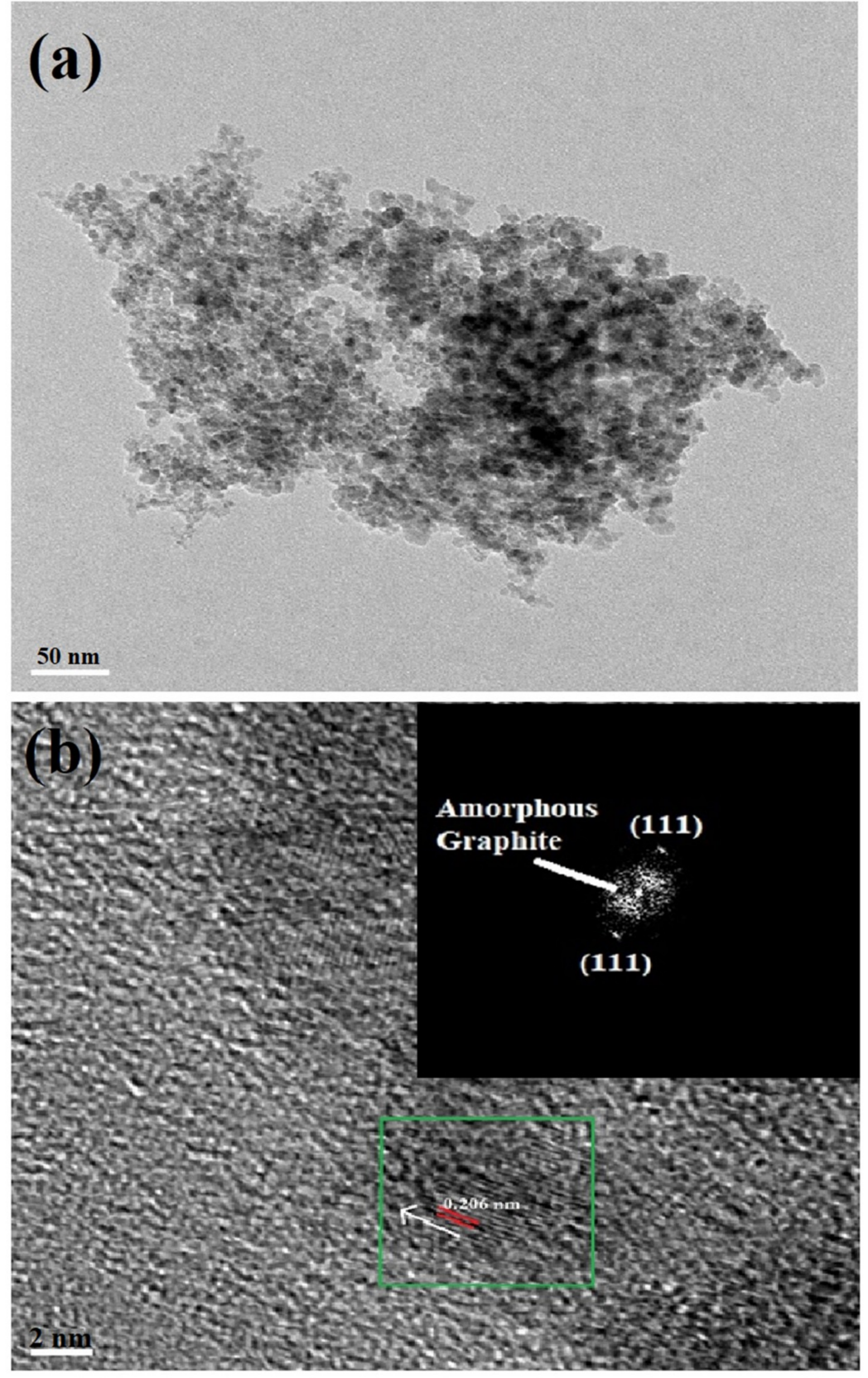

Figure 4. (a) HR-TEM image of NDS1 at agglomerated state shows possible small particles and (b) Diffraction distance $0.206 \mathrm{~nm}$ represents the (111) pattern of nanodiamond along with amorphous graphite existence. 


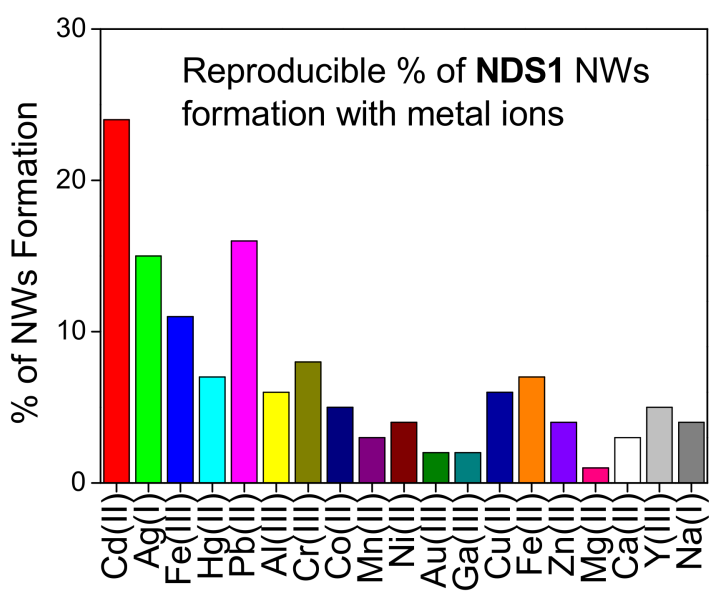

Figure 5. Reproducibility percentage from 100 collected data on DNWs growth with respect to different metal ions.

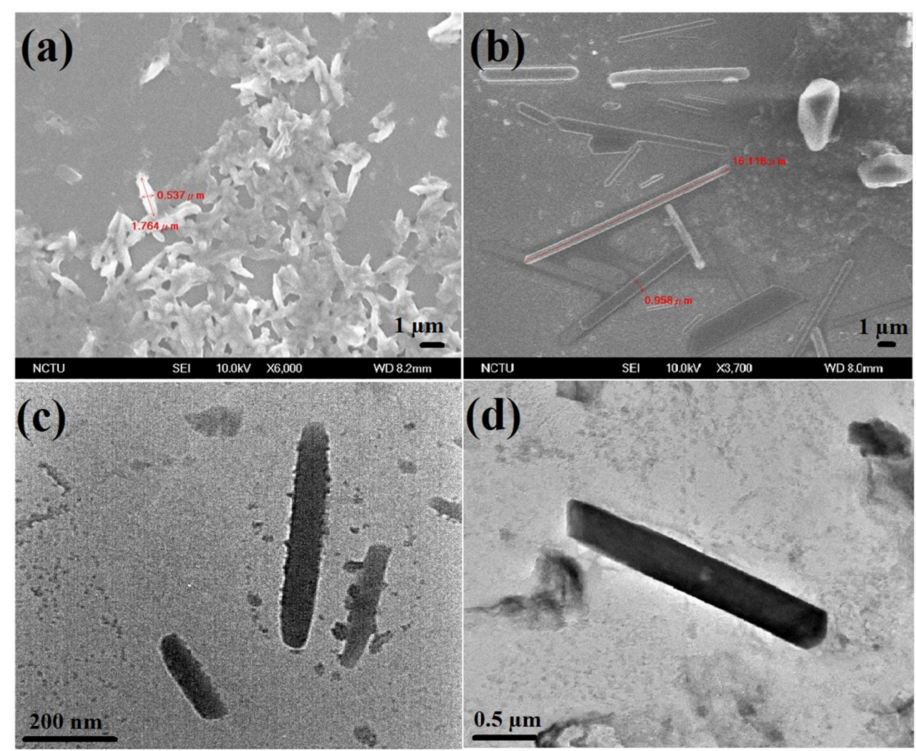

Figure 6. (a) and (b) SEM images of $\mathrm{Cd}^{2+}$-NDS1 NWs $(10 \mu \mathrm{g} / \mathrm{mL}$ in water) at different regions (scale: $1 \mu \mathrm{m})(\mathbf{c})$ and (d) TEM images of $\mathrm{Cd}^{2+}-$ NDS1 NWs $(1 \mathrm{ng} / \mathrm{mL}$ in water) at different regions (scale: 200 $\mathrm{nm}$ and $0.5 \mu \mathrm{m}$, correspondingly).

To establish the semiconducting applicability of $\mathrm{Cd}^{2+}$-NDS1 NWs, characterization of these G-DNWs were carried out as described in the following. Firstly, FTIR spectral interrogations reveal supramolecular interactions between NDS1 and $\mathrm{Cd}^{2+}$ ions. As shown in Figure S14 in supporting information, the $-\mathrm{C}=\mathrm{O}$ stretching of NDS1 is blue shifted to $1681 \mathrm{~cm}^{-1}$ and the amide $-\mathrm{NH}$ band is broadened between 3000 to $3600 \mathrm{~cm}^{-1}$. Note that the free $-\mathrm{SH}$ band of NDS1 at $2562 \mathrm{~cm}^{-1}$ is almost vanished, which may be due to the coordinate bond between -SH of NDS1 and $\mathrm{Cd}^{2+}$ ions. Moreover, the amide -NH bending and asymmetric stretching at 1561 and $1475 \mathrm{~cm}^{-1}$ are blue shifted to 1548 and $1459 \mathrm{~cm}^{-1}$, respectively. It indicates that the NDS1 tends to form NWs in the presence of $\mathrm{Cd}^{2+}$ ions via feasible supramolecular interactions. The feasible repeating units in the $\mathrm{Cd}^{2+}-\mathrm{NDS1} \mathrm{NWs}$ formation is schematically displayed in Figure S15 in supporting information. Due to the stability of the continual organometallic coordination [52] between NDS1 and $\mathrm{Cd}^{2+}$ ions, the G-DNWs can be formed with exceptional morphology, greater lengths and diameters. However, such coordination becomes unstable at higher or lower concentrations or dispersion ratios which lead to mixed structures. This may be due 
to the irregular coordination of NDS1 with $\mathrm{Cd}^{2+}$ ions at these dispersion ratios. Hence it confirms that, at fixed dispersion ratios, the G-DNWs growth with diverse diameters and lengths can be stabilized.

To explain the morphological and conductivity properties of formed G-DNWs, the appearance of $\mathrm{Cd}^{2+}$ ions over the surface of NWs is established from EDX, XPS and XRD spectral investigations. Preliminary analysis of EDX (Figure S16 in supporting information) and Table 1 demonstrate the slightly affected percentile of S (5.22\%), N (14.46\%), O (16.51\%) and C $(51.60 \%)$ than those of the originals, which proves the contributions of $\mathrm{S}, \mathrm{N}$ and $\mathrm{O}$ atoms in the NWs formation. Wherein, reduced content of $\mathrm{C}$ atoms may be attributed to the improved graphitization of NDS1 NWs. Moreover, alteration in the percentage of $\mathrm{C}, \mathrm{S}, \mathrm{N}$ and $\mathrm{O}$ atoms may be attributed to the dislocation of these atoms and the supramolecular coordination with $\mathrm{Cd}^{2+}$ ions, which generate few impurity channels or defects. The EDX spectrum also confirms the existence of $\mathrm{Cd}$ atom $(12.21 \%)$, hence labelled as $\mathrm{Cd}^{2+}{ }_{-N D S 1}$ NWs. Above feasible supramolecular interactions might further accelerate the development of less perfect $\mathrm{sp}^{2}$ graphite layer over $\mathrm{Cd}^{2+}$-NDS1 NWs which may improve the conductivity.

To demonstrate the improved graphitization, the manifestation of $C, N, O, S$ and $C d$ atoms and the involved supramolecular coordination, XPS studies were conducted subsequently. As shown in Figure 7 and Figure S17a in supporting information, C1s peak in the XPS spectra of Cd ${ }^{2+}-N_{D S 1}$ NWs is located at $284.3 \mathrm{eV}$ in contrast to the original at 284.5 and $286.2 \mathrm{eV}$, which confirms the partial graphitization. Disappearance of the peak at $286.2 \mathrm{eV}$ also implies the possible coordination of $-\mathrm{C}=\mathrm{O}$ functional group with $\mathrm{Cd}^{2+}$ atoms. In a similar fashion, N1s, O1s and S2p peaks in the XPS spectra of $\mathrm{Cd}^{2+}$-NDS1 NWs appear at different positions at 399.4, 532.2 and $163.2 \mathrm{eV}$ (Figure S17b-d in supporting information) than that of NDS1, which also confirm their existence and involvement in supramolecular interactions. The contribution of $\mathrm{Cd}^{2+}$ ions and its participation towards supramolecular coordination in NWs formation is evident by the Cd3d peak at $405.2 \mathrm{eV}$ in the XPS spectra displayed in Figure S17e in supporting information. Finally, as shown in Table S1 in supporting information, the XPS interrogations support the proposed schematic from the FTIR analysis.

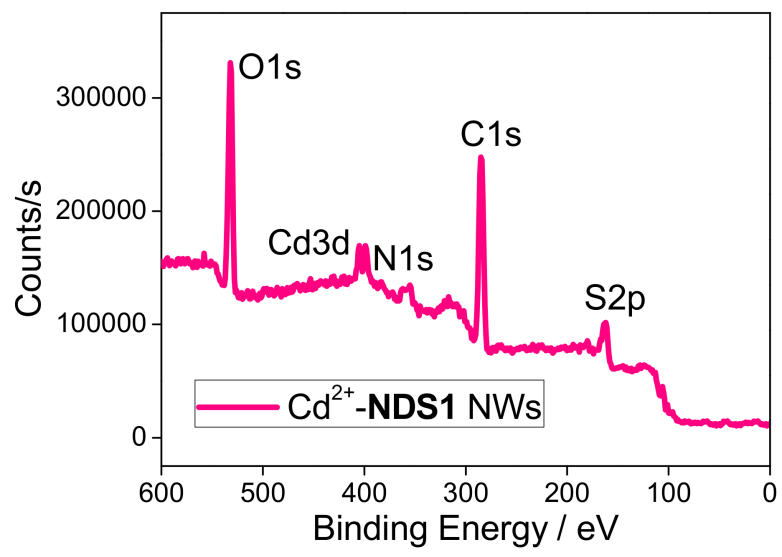

Figure 7. XPS spectrum of $\mathrm{Cd}^{2+}$-NDS1 NWs demonstrates the presence of Carbon (C1s), Nitrogen (N1s), Oxygen (O1s), Sulfur (S2p) and Cadmium (Cd3d) atoms.

The possible supramolecular coordination is further established by TEM and AFM studies, subsequently. As shown in Figure S18a,b in supporting information, TEM images of NDS1 with Cd ${ }^{2+}$ ions over carbon-copper grid reveal the self-assembly of NDS1, which show elongated NWs growth. Above images were obtained by scanning at different regions of $\mathrm{C} / \mathrm{Cu}$ grid at $1 \mathrm{ng} / \mathrm{mL}$ dispersion of NDS1 with $1 \mathrm{nM}$ of $\mathrm{Cd}^{2+}$ ions. In a similar fashion, the AFM images (Figure S18c,d in supporting information) of $\mathrm{Cd}^{2+}$-NDS1 NWs have also verified the self-assembly of NDS1 at $1 \mu \mathrm{g} / \mathrm{mL}$ dispersion of NDS1 with $1 \mu \mathrm{M}$ of $\mathrm{Cd}^{2+}$ ions. These visualized self-assembly of NDS1 is likely to improve the graphitization as explored in XPS analysis. Therefore, it is expected to find out enriched graphitization by means of XRD and Raman surveys. 
The improved graphitization during formation $\mathrm{Cd}^{2+}$-NDS1 NWs was demonstrated through powder XRD investigation. Figure S19 in supporting information reveals the peaks at $2 \theta=43.52,75.28$ and 91.16 degree corresponding to (111), (220) and (311) diffraction patterns of diamond, respectively, along with improved graphitization peak at $2 \theta=26.29$ degree in compared to the NDS1. These processes may also lead to the formation of impurity channels via coordinative binding of $\mathrm{Cd}^{2+}$ ions with NDS1, which may enhance the conductivity. Overall, results from EDX, XPS and XRD studies support the possible supramolecular interactions along with partial graphitization in the $\mathrm{Cd}^{2+}$-NDS1 NWs growth. Next, to demonstrate the improved graphitization, we examined the NW-like assembly of NDS1 mediated by all the metal ions using Raman spectroscopy as described in the following sections.

For Raman studies, $100 \mu \mathrm{M}$ of each metal ion was added to $100 \mu \mathrm{g} / \mathrm{mL}$ dispersion of NDS1 and incubated for $45 \mathrm{~min}$. The final spectra were obtained from 30 collected data via scanning at five different locations of six separate samples. In the presence of metal ions, Raman spectrum of NDS1 exhibits the D and $G$ bands between 1330 1360 and 1590 1610 $\mathrm{cm}^{-1}$, correspondingly, with diverse intensity as shown in Figure S20a in supporting information. Moreover, these cations also show the graphite band between $2600 \sim 3000 \mathrm{~cm}^{-1}$ as displayed in Figure S20b in supporting information. Based on the $\mathrm{D}$ and $\mathrm{G}$ band intensity, the graphitization ratios $\left(\mathrm{I}_{\mathrm{G}} / \mathrm{I}_{\mathrm{D}}\right)$ are calculated and presented in Table $\mathrm{S} 2$ in supporting information. From Raman investigations of NDS1 with all metal ions, the $\mathrm{Cd}^{2+}$ ions show the improved graphitization via highly intense $G$ band at $1585 \mathrm{~cm}^{-1}$ and less intense D band at $1381 \mathrm{~cm}^{-1}$. In contrast to other ions, $\mathrm{Cd}^{2+}$ ions reduce the $\mathrm{D}$ band intensity and enhance the $\mathrm{G}$ band intensity, which indicates the possible enhancement of graphitization. The intensity of the graphite band between $2600 \sim 3000 \mathrm{~cm}^{-1}$ of NDS1 with $\mathrm{Cd}^{2+}$ ions is clearly stronger than those of other ions. As presented in Table $\mathrm{S} 2$, the $\mathrm{I}_{\mathrm{G}} / \mathrm{I}_{\mathrm{D}}$ ratio of $\mathrm{Cd}^{2+}$-NDS1 NWs is 1.27 , which is greater than those NDS1 NWs assemblies formed with the remaining metal ions. Hence it is chosen for the following electrical conductivity measurements. Note that the described graphitization enrichment in $\mathrm{Cd}^{2+}{ }_{-}$NDS1 NWs, which plays vital role in the conductivity studies, may also affect its morphology along with the formation of impurity channels. The surface morphology and impurity channels were visualized by HR-TEM measurements at $1 \mathrm{ng} / \mathrm{mL}$ dispersion of NDS1 with $1 \mathrm{nM}$ of $\mathrm{Cd}^{2+}$ ions as explained in the following.

The graphite sheath wrapping over the diamond core of $\mathrm{Cd}^{2+}$-NDS1 NWs and the existence of impurity channels are well demonstrated by HR-TEM and FT diffraction analysis, as shown in Figure 8. HR-TEM images of a single $\mathrm{Cd}^{2+}$-NDS1 NW show improvement in morphology, which may due to a rigid diamond core. Under high magnifications, diffraction distances of $0.206 \mathrm{~nm}$ and 0.126 $\mathrm{nm}$ are determined and are assigned to (111) and (202) pattern of diamond, respectively. Moreover, above HR-TEM images (Figure 8) also show impurity channels or defective voids (green circles) along with graphite sheath (red circles). These observations suggest that the formed NWs possess more diamond-like characteristics with slight enrichment of graphite and impurity channels, which lead to longer NWs formation in contrast to previous reports. These impurity channels may arise from the presence of $\mathrm{Cd}^{2+}$ ions and wet chemical synthesis. The visualization of diamond core of $\mathrm{Cd}^{2+}$-NDS1 NWs through the HR-TEM studies is not considerably affected by the presence of amorphous and less perfect $\mathrm{sp}^{2}$ graphitic layer and impurity channels, which also propose fewer graphite sheath wrapping. On the contrary, the G-DNWs grown by the CVD may have less perfect $\mathrm{sp}^{2}$ graphite layer and impurity channels over $\mathrm{sp}^{3}$ diamond core at diverse ratios. Nevertheless, the Cd $\mathrm{d}^{2+}$-NDS1 NWs with more diamond-like characteristics must have lower conductivity and will be discussed later. 


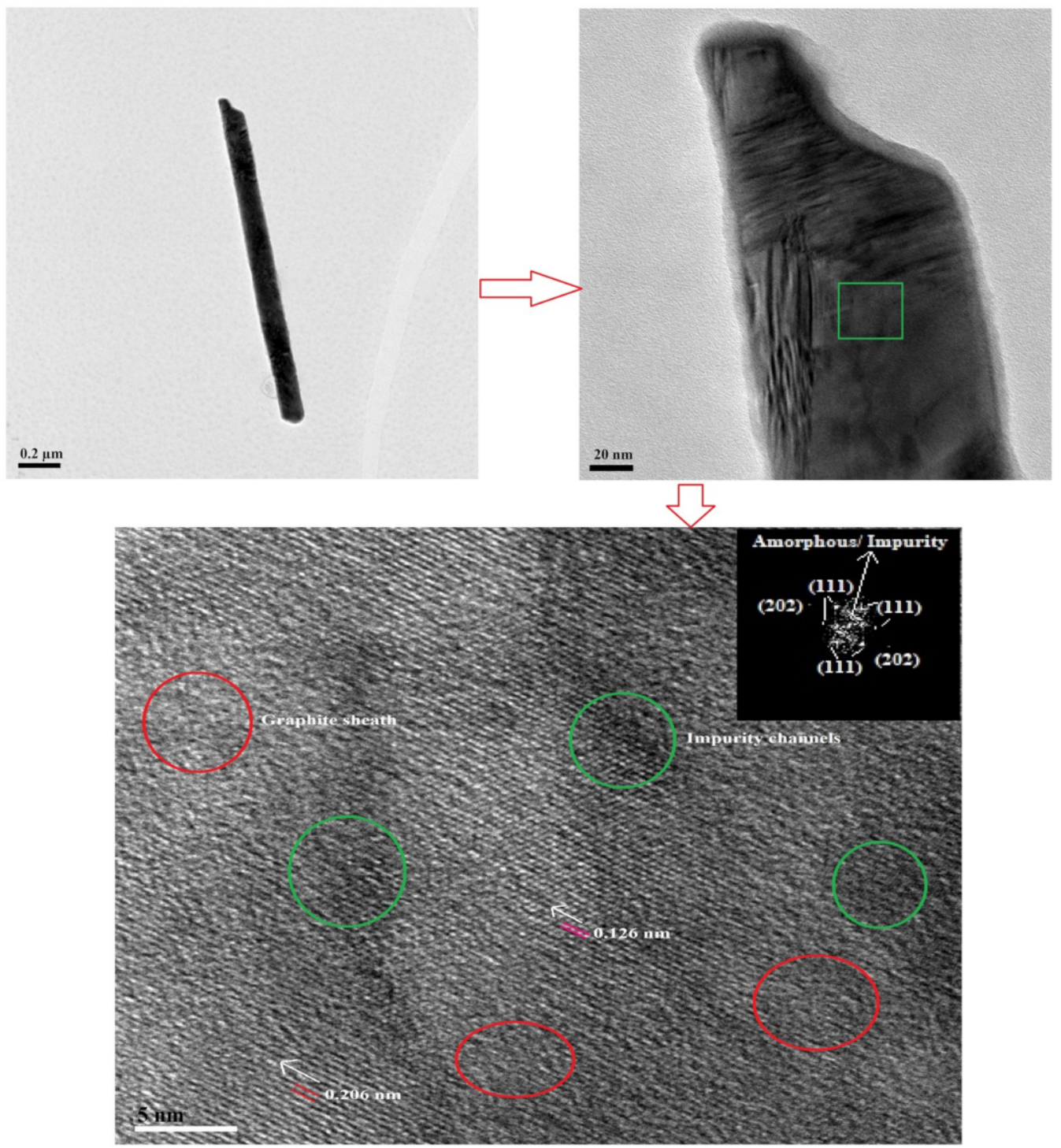

Figure 8. HRTEM images of single $\mathrm{Cd}^{2+}$-NDS1 NW obtained at $1 \mathrm{ng} / \mathrm{mL}$ dispersion in water indicate the presence of graphite sheath (red circles) and impurity channels (green circles). The diffraction distances $0.206 \mathrm{~nm}$ and $0.126 \mathrm{~nm}$ are related to (111) and (202) patterns of nanodiamond (Scale: $0.2 \mu \mathrm{m}$, $20 \mathrm{~nm}$ and $5 \mathrm{~nm}$, correspondingly).

From FTIR, XPS, TEM and AFM studies, the mechanism behind the $\mathrm{Cd}^{2+}$-NDS1 NWs growth can be explained as follows. In the presence of $\mathrm{Cd}^{2+}$ ions, the DNWs growth is initiated through supramolecular interactions with the functional units $(-\mathrm{C}=\mathrm{O},-\mathrm{NH}$ and $-\mathrm{SH})$ of partially graphitized NDS1 particles, which may further induce the self-assembly and lead to formation of NWs. During the $\mathrm{Cd}^{2+}$-NDS1 NWs growth, $\mathrm{Cd}^{2+}$ ions act as initiative and supramolecular binding source to boost the self-assembly and graphene shells formation and impurity channels. These graphene shells and impurity channels may appear over the surface and further sandwich between the NDS1 particles and hence generate less perfect $\mathrm{sp}^{2}$ graphite wrapping over the DNWs. The presence of these graphene shells on the less perfect graphite layer and the impurity channels might act as the connecting units between diamond cores of the DNWs. Due to the supramolecular self-assembly of dissimilar sized NDS1, the $\mathrm{Cd}^{2+}$-NDS1 NWs are grown with various lengths and diameters. However, the supramolecular assembly may enhance rigidity by avoiding the formation of excess graphene shells and impurity channels over the NWs, which reveal more diamond-like characteristics. Due to 
the rigidness, smoothness and diamond-like characteristics, the conductivity of $\mathrm{Cd}^{2+}$-NDS1 NWs may be affected considerably as demonstrated next.

To authenticate the hybrid G-DNWs formation, conductivity measurements were conducted on a single $\mathrm{Cd}^{2+}$-NDS1 NW device (as shown in Figure 9A) on a $\mathrm{Si} / \mathrm{SiO}_{2}$ wafer via the fabrication processes illustrated in Figure 9B. The fabrication processes include pads design, alignment marks, DNWs dispersion, $\mathrm{Au} / \mathrm{Ti}$ contacts deposition and interconnections of single NW (Figures S21-S24 in supporting information) as previously described in Section 2.2. SEM image of the selected single $\mathrm{Cd}^{2+}$-NDS1 NW with designed structures of $\mathrm{N}-\mathrm{Si} / \mathrm{SiO}_{2} / \mathrm{Cd}^{2+}-\mathrm{NDS} 1 \mathrm{NW} / \mathrm{Au}$ is displayed in Figure 10a. The selected $\mathrm{Cd}^{2+}$-NDS1 NW has an overall length of $7.7 \mu \mathrm{m}$ with a diameter of $400 \mathrm{~nm}$. The single $\mathrm{Cd}^{2+}{ }_{-}$NDS1 NW is divided into three sections, namely, L1 $(2.22 \mu \mathrm{m}), \mathrm{L} 2(1.12 \mu \mathrm{m})$ and L3 $(1.34 \mu \mathrm{m})$ by the contacts 1 to 4 .

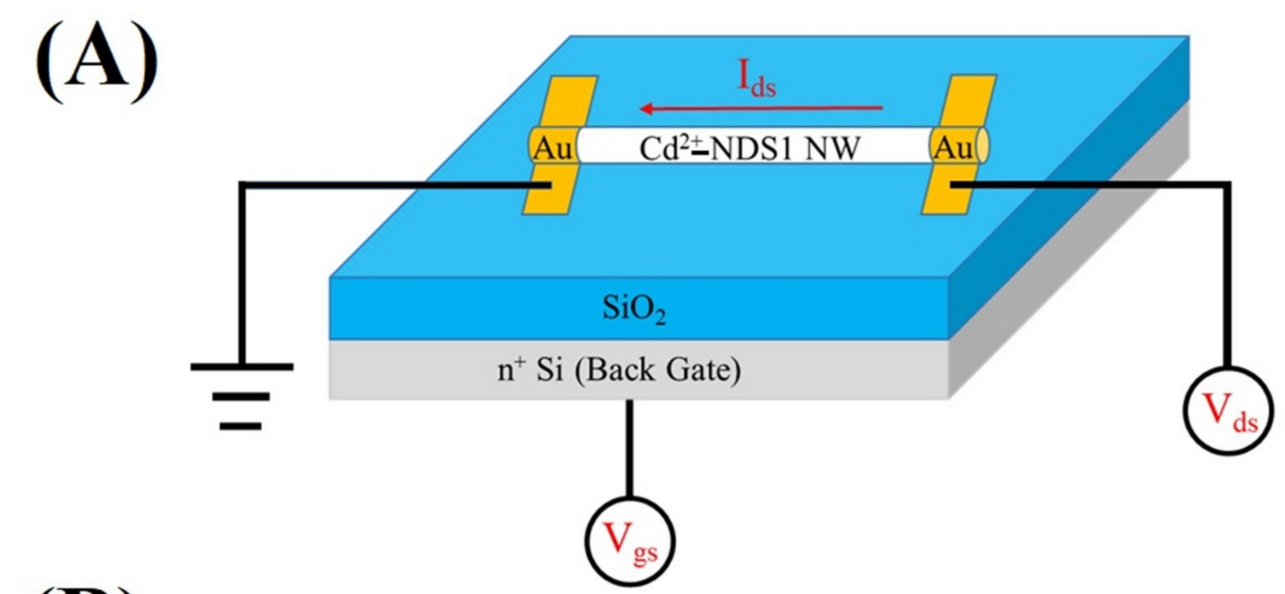

(B)
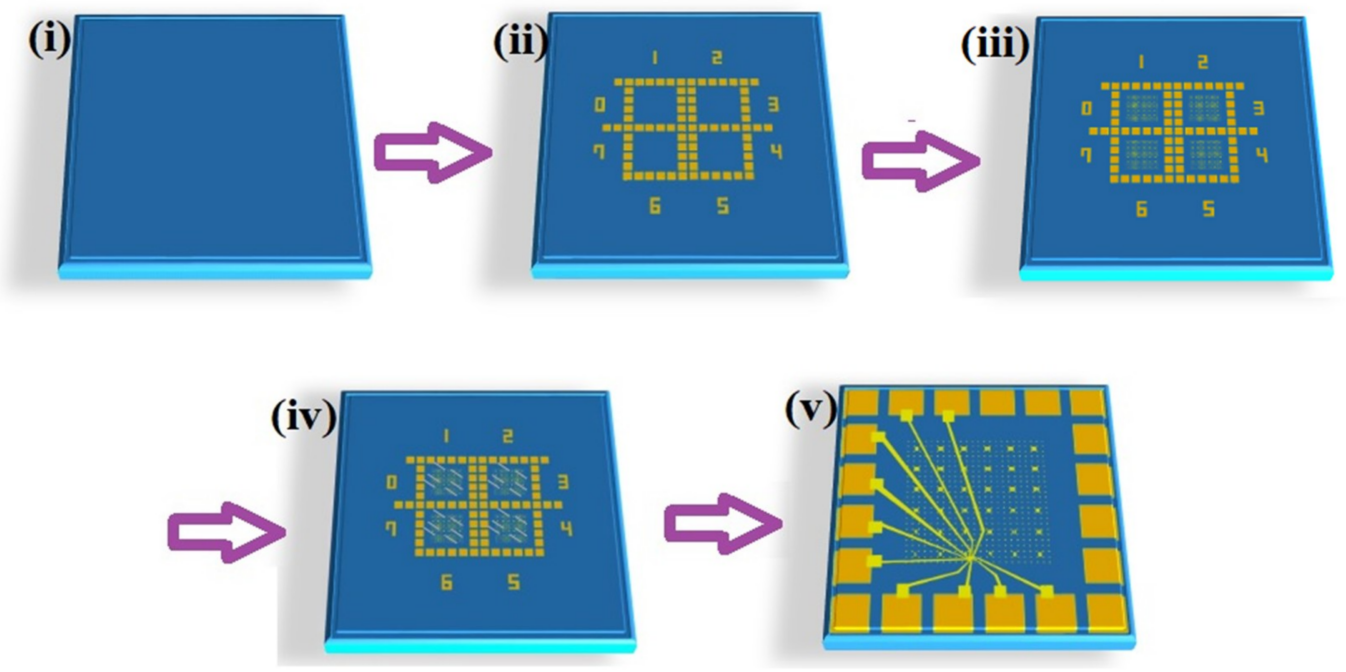

Figure 9. (A) Schematic of a single $\mathrm{Cd}^{2+}$-NDS1 NW device and (B) Steps involved in fabrication are

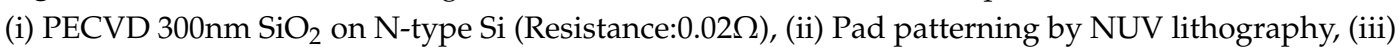
Alignment mark patterning by E-beam lithography (iv) Nanowires dispersion followed by FIB and (v) Interconnection patterning by E-beam lithography. 

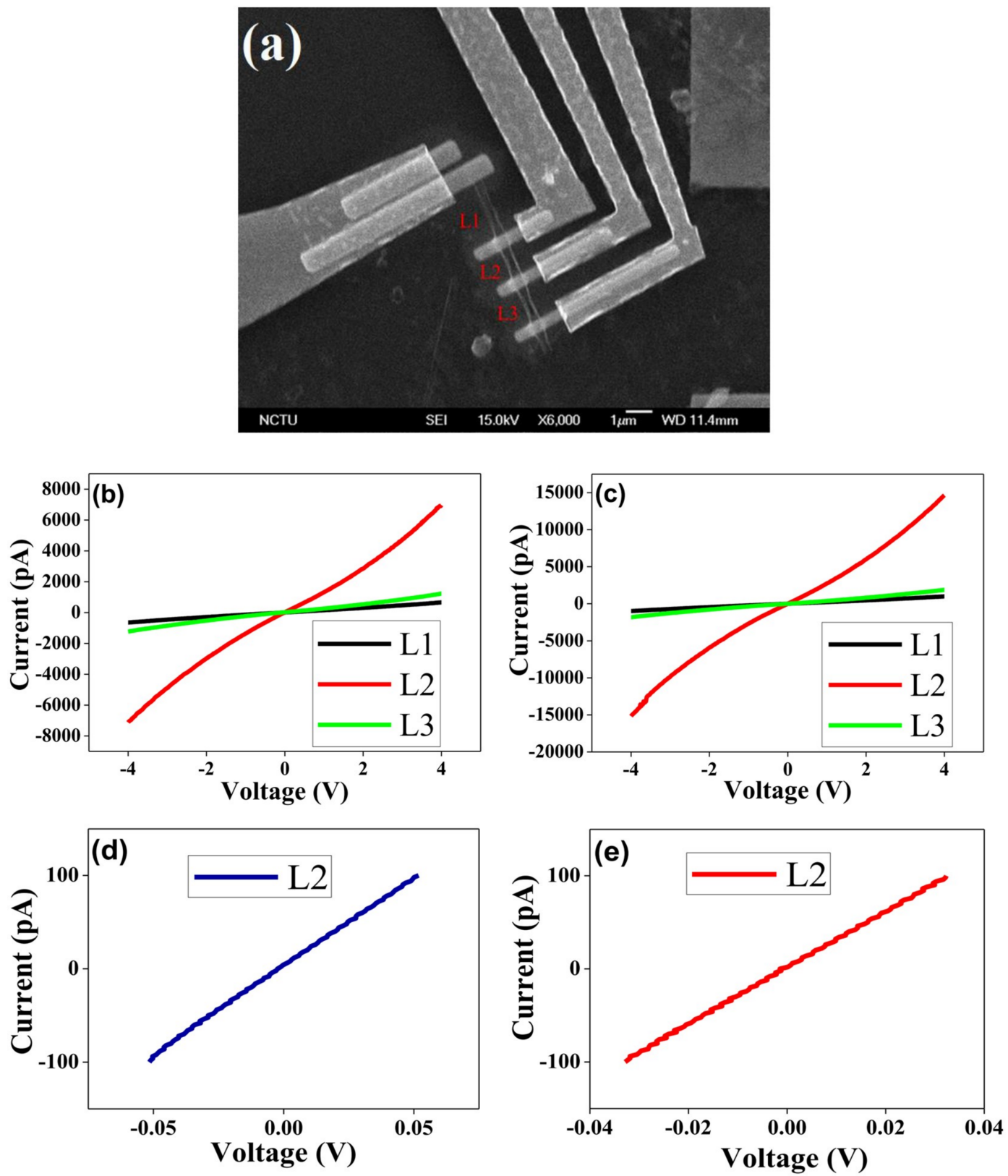

Figure 10. (a) SEM image of the single $\mathrm{Cd}^{2+}$-NDS1 NW with Au contacts. I-V curves of L1, L2 and L3 measured using a two-point probe at $300 \mathrm{~K}$ in (b) air (760 torr) and (c) vacuum $\left(10^{-2}\right.$ torr). I-V curves of L2 measured using a four-point probe at $300 \mathrm{k}$ in (d) air (760 torr) and (e) vacuum $\left(10^{-2}\right.$ torr).

A 196-Model cryogenic probe station was utilized to evaluate the conductivity properties of L1, L2 and L3. The resistivity and conductivity from the I-V characteristics were calculated [53] using following Equations (3) and (4).

$$
\sigma=1 / \rho
$$

and

$$
\rho=R(A / 1)
$$

where $\sigma$ represents the conductivity in $S / \mathrm{cm}$ and $\rho$ is recognized as the static resistivity obtained from Equation (4); $\mathrm{R}$ is known as electrical resistance of a specimen in $\Omega$, A represents the cross-sectional area of the specimen in $\mathrm{m}^{2}$ and 1 is the length of material in meter. 
These NW portions were scanned between -4 and $4 \mathrm{~V}$ and their conductivity was measured in air (760 torr) and vacuum ( $10^{-2}$ torr) conditions, as shown in Figure $10 \mathrm{~b}, \mathrm{c}$. As displayed in Table 2, the measured conductivity of L2 in air and vacuum possesses a conductivity of $1.15 \times 10^{-4}$ and $2.31 \times 10^{-4} \mathrm{mS} / \mathrm{cm}$ with coefficient of variations of $20 \%$ and $11 \%$, respectively. These values are better than those of L1 and L3 under the same conditions. As shown in Figure 10d,e, the obtained conductivity results further confirm that L2 shows a better conductivity in vacuum than that of in air. The dissimilar behavior in conductivity of the L1 and L3 portions is evident due to the irregular graphite sheath wrapping. Different degree of graphite sheath/graphene shells coverage over L1 and L3 is attributed to the supramolecular assembly of the NDS1 NPs with dissimilar sizes in the presence of $\mathrm{Cd}^{2+}$ ions, as illustrated in aforementioned HR-TEM studies. However, the conductivity obtained from L2 is lower than that of $\mathrm{pH}$ induced G-DNWs [36] because of the utilization of diverse functional units and growth approaches. Wherein, the NDS1 with altered functional units are supramolecularly assembled in the presence of $\mathrm{Cd}^{2+}$ ions and induce NWs growth with more diamond-like characteristics and mild graphite sheath wrapping. The more diamond-like characteristics may lead to the growth of rigid NWs with smooth morphology as evident in the HR-TEM images but with lower conductivity in compared to the ND-Cys NWs. To investigate the transport mechanisms in L2, temperature-dependent conductivity $(\mathrm{I}-\mathrm{V})$ measurements were engaged between $80 \sim 300 \mathrm{~K}$. The conductivity decreases with decreasing temperature as shown in Figure 11 and Figure S25 (in supporting information).

Table 2. Resistance, resistivity and conductivity data of L1, L2 and L3 sections of a selected Cd ${ }^{2+}$ NDS1 NW with four contacts.

\begin{tabular}{cccccc}
\hline $\begin{array}{c}\text { Device Measurement } \\
\text { Condition }\end{array}$ & $\begin{array}{c}\mathbf{C d}^{2+} \text {-NDS1 } \\
\text { NW Area }\end{array}$ & $\begin{array}{c}\text { Resistance } \\
(\mathbf{G} \cdot \mathbf{\Omega})\end{array}$ & $\begin{array}{c}\text { Resistivity } \\
(\mathbf{\Omega} \cdot \mathbf{c m})\end{array}$ & $\begin{array}{c}\text { Conductivity } \\
(\mathbf{m S} / \mathbf{c m})\end{array}$ & $\begin{array}{c}\text { Coefficient of } \\
\text { Variation }\end{array}$ \\
\hline \multirow{3}{*}{ Atmosphere (760 torr) } & L1 & 7.02 & $3.98 \times 10^{4}$ & $2.51 \times 10^{-5}$ & $0.66 \%$ \\
& L2 & 0.78 & $8.70 \times 10^{3}$ & $1.15 \times 10^{-4}$ & $0.20 \%$ \\
& L3 & 4.39 & $4.10 \times 10^{4}$ & $2.44 \times 10^{-5}$ & $0.51 \%$ \\
Vacuum $\left(10^{-2}\right.$ torr) & L1 & 4.55 & $2.58 \times 10^{4}$ & $3.88 \times 10^{-5}$ & $0.74 \%$ \\
& L2 & 0.39 & $4.33 \times 10^{3}$ & $2.31 \times 10^{-4}$ & $0.11 \%$ \\
\hline
\end{tabular}

The observed linear and symmetrical I-V behaviors of L2 throughout the entire temperature range indicate good ohmic contacts. The obtained conductivity is resulted from the $\mathrm{sp}^{2}$ graphene shells, impurity channels and $\mathrm{Cd}^{2+}$ ions over the G-DNW surface and in the core. The conductivity may also be affected by the presence of sulfur $(\mathrm{S})$ and Nitrogen $(\mathrm{N})$ atoms on the surface of $\mathrm{Cd}^{2+}$-NDS1 NWs. The temperature-dependent electrical resistance and static resistivity decrease as the temperature is increased from $80 \mathrm{~K}$ to $300 \mathrm{~K}$, as shown in Figure S26a,b in supporting information. By fitting the plots of "lnR vs. 1/T" (Figure S27a-c in supporting information), the activation energies $\left(\mathrm{E}_{\mathrm{a}}\right)$ with values of $29.41 \mathrm{meV}$ and $12.43 \mathrm{meV}$ for L2 are determined for temperature ranges of 300 200 K and 200 80 K, respectively, which clearly indicates that two kinds of transport mechanisms are involved [54]. In addition, the plot of "ln $\sigma$ Vs $1 / \mathrm{T}$ " (Figure S27d in supporting information) also support the manifestation of different transport mechanisms in the temperature-dependent conductivity studies. In order to further investigate the electron transport mechanisms, plots of "conductivity $V s \quad 1 / \mathrm{T}^{\prime}$ and "lnR $V_{S} \mathrm{~T}^{-(1 / 4) " ~ a r e ~ f i t t e d ~ n o n l i n e a r l y ~ a n d ~ l i n e a r l y, ~ a s ~ s h o w n ~ i n ~ F i g u r e ~ S 28 a, b ~ i n ~ s u p p o r t i n g ~ i n f o r m a t i o n . ~}$ Similarly, a plot of "ln $\sigma$ V $\mathrm{T}^{-(1 / 4) " ~(F i g u r e ~ 12 a) ~ i s ~ c o n v e r t e d ~ t o ~ a ~ p l o t ~ o f ~ " e n e r g y ~(E) ~ V s ~ t e m p e r a t u r e ~(T) " ~}$ (Figure 12b). By using the aforementioned Equation (2), it can be confirmed that, between $200 \sim 80 \mathrm{~K}$, the electron transport is dominated by 3D-mott variable-range hopping [55]. However, at temperature above $200 \mathrm{~K}$, the transport mechanism is governed by thermal activation [56]. 


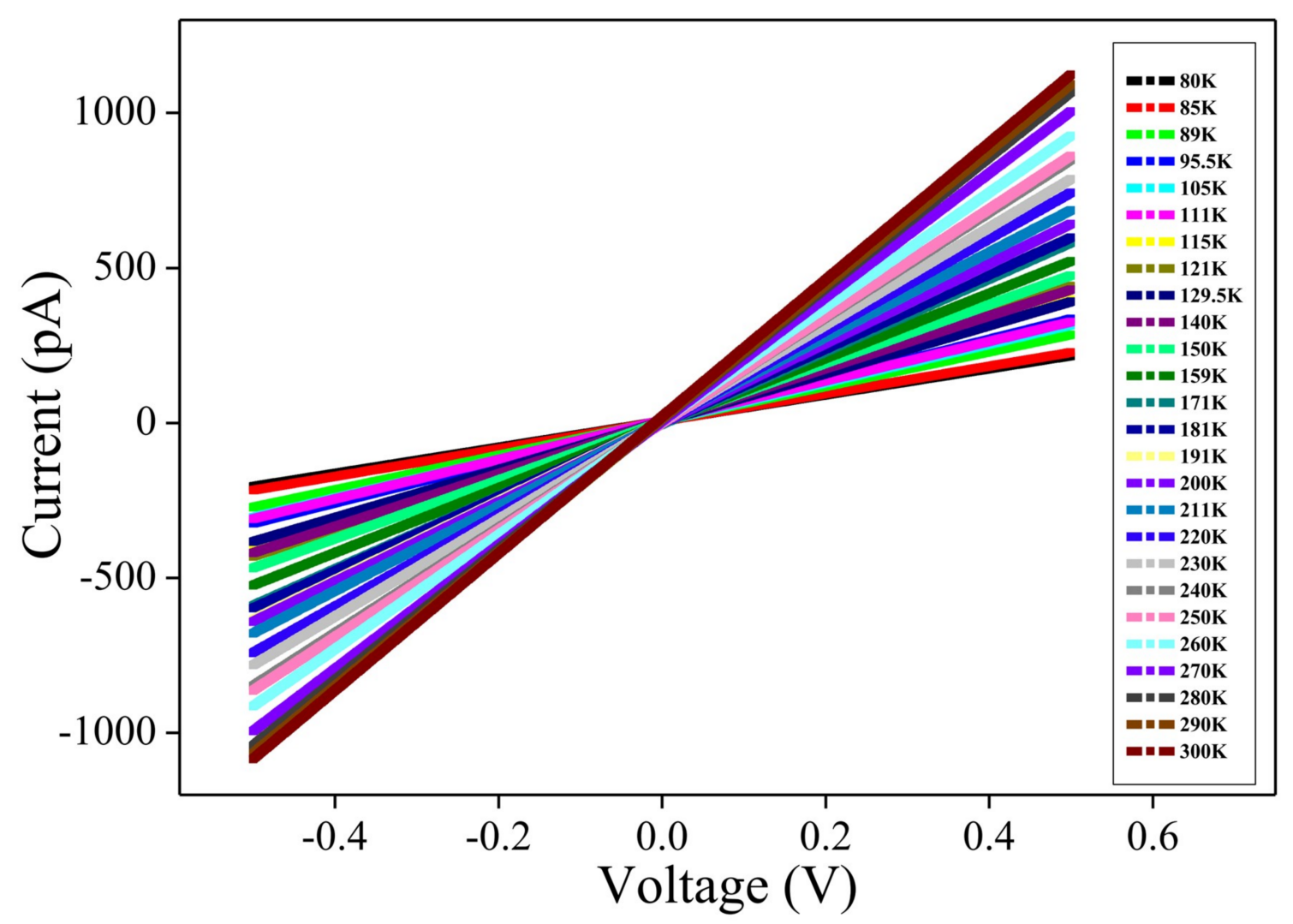

Figure 11. Temperature-dependent current-voltage (I-V) curves for $\mathrm{Cd}^{2+}$-NDS1 NW-L2 (2-contacts, 2-point probe in vacuum $\left(10^{-2}\right.$ torr $\left.)\right)$ between $80 \sim 300 \mathrm{k}$.
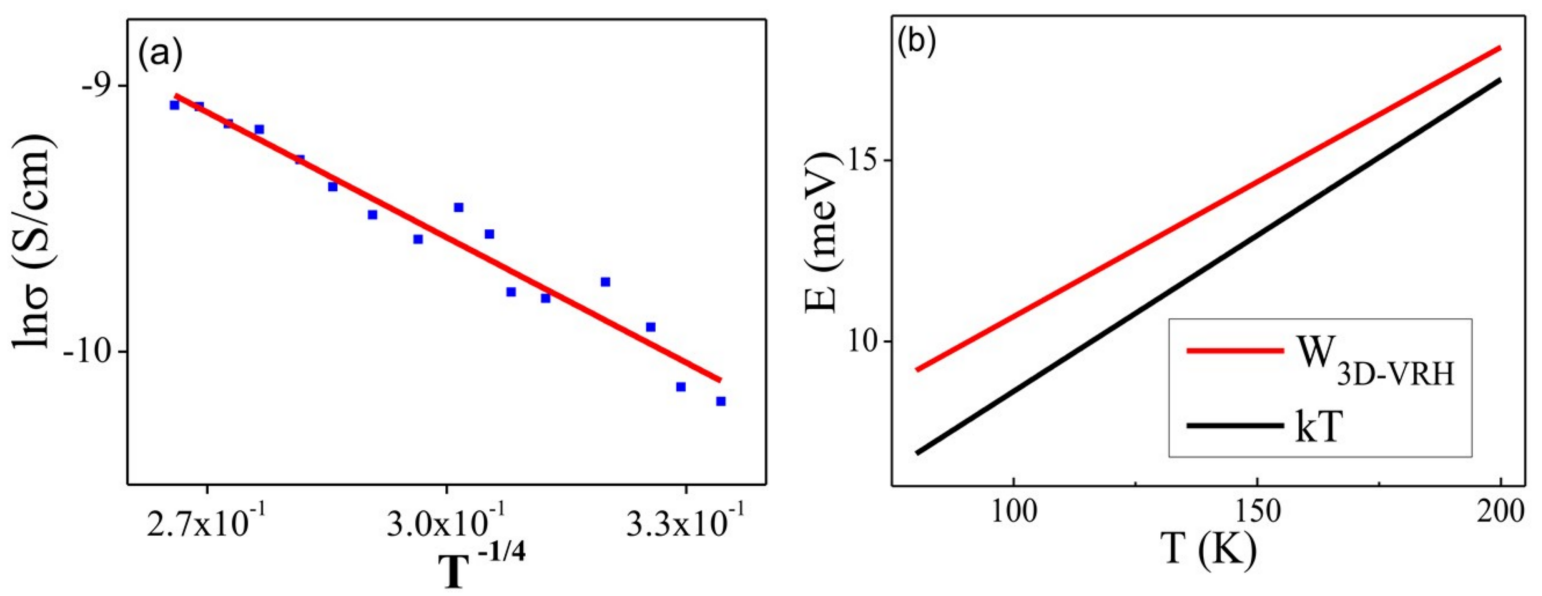

Figure 12. (a) Plot of "ln $\sigma V_{s} \mathrm{~T}^{-1 / 4}$ " for $\mathrm{Cd}^{2+}-\mathrm{NDS1} \mathrm{NW}$ (L2) between 200-80 K and (b) Plot of "E Vs $\mathrm{T}^{\prime}$ ' derived from "ln $\sigma V_{s} \mathrm{~T}^{-1 / 4}$ " represents the linear fittings of "Mott's 3D hopping energy (red line)" and thermal energy (black line) obtained from Equation (2).

Between $200 \sim 80 \mathrm{~K}$, hopping of electrons is supported by the coexisting impurity channels $/ \mathrm{Cd}^{2+}$ ions and graphene shells over NDS1 surface. On the other hand, between 200 300 K, the electrical conductivity is mostly contributed by the thermally activated impurities or less perfect $\mathrm{sp}^{2}$ graphite layer over $\mathrm{Cd}^{2+}$-NDS1 NW. Finally, the transconductance measurements between -4 to $4 \mathrm{~V}$ from the metal-oxide-semiconductor field-effect transistor (MOSFET) [57] structures of L1, L2 and L3 reveal that the NW conductivity cannot be modulated by the applied gate bias (Figures S29-S31 in supporting 
information) due to the inferior quality of the interface and/or poor carrier concentrations of the $\mathrm{Cd}^{2+}$-NDS1 NWs.

The drain-source current $\left(\mathrm{I}_{\mathrm{ds}}\right)$ is completely dominated by the gate leakage current when gate bias is higher than $15 \mathrm{~V}$ because of the poor NW/SiO2 interface. However, modulation of the transconductance of the MOSFET will be possible if suitable dielectric material with improved interface properties with the NWs was found in the future. As summarized in Table 3, values of our NW resistivity are in between those of the diamond carbon nanotubes and diamond based electrical resistivity studies [58-64]. The current $\mathrm{Cd}^{2+}$-NDS1 NWs also have a lower resistivity than that of our previous reported uneven G-DNW (ND-Cys NW) via $\mathrm{pH}$-induced assembly. These $\mathrm{Cd}^{2+}$-NDS1 NWs possess rigidness and smooth surface morphology, which lead to the insufficient $\mathrm{sp}^{2}$ graphitic layer over diamond and hence slightly reduced conductivity. Therefore, we are currently working towards the development of novel G-DNWs by combining both tactics that can cultivate G-DNWs with both flatten morphology and improved electrical conductivity.

Table 3. Comparative account on electrical resistivities of $\mathrm{Cd}^{2+}$ - NDS1 NW with respect to selected diamond materials, carbon nanotube and carbon nanowire from I-V measurements.

\begin{tabular}{cccc}
\hline Materials & $\begin{array}{c}\text { Growth } \\
\text { Route/Technique }\end{array}$ & $\begin{array}{c}\text { Electrical Resistivity } \\
(\Omega-\mathbf{c m})\end{array}$ & Ref \\
\hline Single ND-Cys G-DNW & Wet-Chemical Synthesis & 370.76 & {$[36]$} \\
ND-Cys + Hg' ${ }^{2+}$ assembly & Wet-Chemical Synthesis & NA & {$[42]$} \\
Undoped-UNCD & NA & $10^{6}$ & {$[58]$} \\
Single Crystal Diamond & Commercial Source & $10^{14}$ & {$[59]$} \\
Ultra-thin Nanocrystalline Diamond Films & MPCVD & $5 \times 10^{13}$ & {$[60]$} \\
Nitrogen Incorporated Diamond Films & MPCVD & $10^{5}$ & {$[61]$} \\
Single Diamond Nanowire & APCVD & NA & {$[63]$} \\
Carbon Nanotube & Carbon-arc Method & $10^{-3} \sim 10^{-6}$ & {$[64]$} \\
Carbon Nanowire & NA & 0.015 & This Work \\
Single Cd ${ }^{2+}$-NDS1 NW & Wet-Chemical Synthesis & $4.33 \times 10^{3}$ &
\end{tabular}

\section{Conclusions}

The 4-Amino-5-phenyl-4H-1,2,4-triazole-3-thiol (S1) functionalized diamond nanoparticles (NDS1) is synthesized and employed in metal ions mediated self-assembly directed hybrid graphite-DNWs growth. In the presence of $\mathrm{Cd}^{2+}$ ions, G-DNWs are formed with $24 \%$ reproducibility, which is higher than that of other metal ions. The $\mathrm{Cd}^{2+}$-NDS1 NWs have diameters between 50 to 980 $\mathrm{nm}$ and lengths between $100 \mathrm{~nm} \sim$ hundreds of microns. Involvement of supramolecular coordination in the self-assembly of $\mathrm{Cd}^{2+}$ contributed NDS1 particles towards NWs growth is supported by FTIR, EDX and XPS results. Graphite wrapping, impurity channels and existence of $\mathrm{Cd}^{2+}$ ions over the DNWs surface are clearly demonstrated by EDX, XPS, Raman, XRD and TEM results. The $\mathrm{Cd}^{2+}$ mediated supramolecular assembly of NDS1 towards G-DNWs construction is well supported by TEM and AFM investigations. The as-grown G-DNWs show rigid diamond characteristics with smooth morphology, which is evident in the HR-TEM images. A single $\mathrm{Cd}^{2+}{ }_{-}$NDS1 NW device is fabricated to conduct I-V measurements and to determine its applicability. In vacuum, the conductivity of L2 section in the single G-DNW is determined with a value of $2.31 \times 10^{-4} \mathrm{mS} / \mathrm{cm}$. Temperature-dependent conductivity studies of the single $\mathrm{Cd}^{2+}$-NDS1 NW portion L2 reveal that the carrier transport mechanism is dominated by 3D-mott variable-range hopping between $200 \sim 80 \mathrm{~K}$ with an activation energy of 29.41 $\mathrm{meV}$. However, at higher temperature between $200 \sim 300 \mathrm{~K}$, the transport mechanism becomes thermally activate with an activation energy of $12.43 \mathrm{meV}$. This new strategy for the growth of rigid G-DNWs with smooth morphology may further promote the diamond NW-based semiconductor research. 
Supplementary Materials: The Supplementary Materials are available online at http:/ /www.mdpi.com/20794991/9/3/415/s1.

Author Contributions: M.S., Y.-C.C. and K.W.S. designed the experiment. Y.-C.C. and L.-C.L. fabricated the device and conducted the electrical measurements. T.S. and F.-H.K. performed the DLS studies. M.S. performed the synthesis, Microscopic, Raman and XRD experiments. M.S. and K.W.S. wrote the manuscript and all authors have given approval to the final version of the manuscript.

Funding: The authors are grateful to Ministry of Science and Technology of Taiwan for financial support under the contract MOST 107-2811-M-009-015 and MOST 105-2112-M-009-005-MY3.

Conflicts of Interest: The authors declare no conflict of interest.

\section{References}

1. Long, Y.-Z.; Yu, M.; Sun, B.; Gu, C.-Z.; Fan, Z. Recent advances in large-scale assembly of semiconducting inorganic nanowires and nanofibers for electronics, sensors and photovoltaics. Chem. Soc. Rev. 2012, 41, 4560-4580. [CrossRef] [PubMed]

2. Dasgupta, N.P.; Sun, J.; Liu, C.; Brittman, S.; Andrews, S.C.; Lim, J.; Gao, H.; Yan, R.; Yang, P. 25th Anniversary Article: Semiconductor Nanowires-Synthesis, Characterization, and Applications. Adv. Mater. 2014, 26, 2137-2184. [CrossRef] [PubMed]

3. Tran, D.P.; Pham, T.T.T.; Wolfrum, B.; Offenhäusser, A.; Thierry, B. CMOS-Compatible Silicon Nanowire Field-Effect Transistor Biosensor: Technology Development toward Commercialization. Materials 2018, 11, 785. [CrossRef] [PubMed]

4. Zhang, X.; Liu, C.; Ren, G.; Li, S.; Bi, C.; Hao, Q.; Liu, H. High-Switching-Ratio Photodetectors Based on Perovskite $\mathrm{CH}_{3} \mathrm{NH}_{3} \mathrm{PbI}_{3}$ Nanowires. Nanomaterials 2018, 8, 318. [CrossRef] [PubMed]

5. Yan, R.; Gargas, D.; Yang, P. Nanowire photonics. Nat. Photonics 2009, 3, 569-576. [CrossRef]

6. Zhong, Z.; Qian, F.; Wang, D.; Lieber, C.M. Synthesis of p-Type Gallium Nitride Nanowires for Electronic and Photonic Nanodevices. Nano Lett. 2003, 3, 343-346. [CrossRef]

7. Garnett, E.C.; Brongersma, M.L.; Cui, Y.; McGehee, M.D. Nanowire Solar Cells. Annu. Rev. Mater. Res. 2011, 41, 269-295. [CrossRef]

8. Hochbaum, A.I.; Yang, P. Semiconductor Nanowires for Energy Conversion. Chem. Rev. 2010, 110, 527-546. [CrossRef] [PubMed]

9. Scheibel, T.; Parthasarathy, R.; Sawicki, G.; Lin, X.-M.; Jaeger, H.; Lindquist, S.L. Conducting nanowires built by controlled self-assembly of amyloid fibers and selective metal deposition. Proc. Nat. Acad. Sci. USA 2003, 100, 4527-4532. [CrossRef] [PubMed]

10. Hsu, P.-C.; Wang, S.; Wu, H.; Narasimhan, V.K.; Kong, D.; Lee, H.R.; Cui, Y. Performance enhancement of metal nanowire transparent conducting electrodes by mesoscale metal wires. Nat. Commun. 2013, 4, 2522. [CrossRef] [PubMed]

11. Macias-Montero, M.; Filippin, A.N.; Saghi, Z.; Aparicio, F.J.; Barranco, A.; Espinos, J.P.; Frutos, F.; Gonzalez-Elipe, A.R.; Borras, A. Vertically Aligned Hybrid Core/Shell Semiconductor Nanowires for Photonics Applications. Adv. Funct. Mater. 2013, 23, 5981-5989. [CrossRef]

12. Briseno, A.L.; Holcombe, T.W.; Boukai, A.I.; Garnett, E.C.; Shelton, S.W.; Fréchet, J.J.M.; Yang, P. Oligo- and Polythiophene/ZnO Hybrid Nanowire Solar Cells. Nano Lett. 2010, 10, 334-340. [CrossRef] [PubMed]

13. Pescaglini, A.; Iacopino, D. Metal nanoparticle-semiconductor nanowire hybrid nanostructures for plasmon-enhanced optoelectronics and sensing. J. Mater. Chem. C 2015, 3, 11785-11800. [CrossRef]

14. Wang, X.; Sumboja, A.; Lin, M.; Yan, J.; Lee, P.S. Enhancing electrochemical reaction sites in nickel-cobalt layered double hydroxides on zinc tin oxide nanowires: A hybrid material for an asymmetric supercapacitor device. Nanoscale 2012, 4, 7266-7272. [CrossRef] [PubMed]

15. Szunerits, S.; Coffinier, Y.; Boukherroub, R. Diamond Nanowires: A Novel Platform for Electrochemistry and Matrix-Free Mass Spectrometry. Sensors 2015, 15, 12573-12593. [CrossRef] [PubMed]

16. Yu, Y.; Wu, L.; Zhi, J. Diamond Nanowires: Fabrication, Structure, Properties, and Applications. Angezw. Chem. Int. Ed. 2014, 53, 14326-14351. [CrossRef] [PubMed]

17. Vlasov, I.; Lebedev, O.I.; Ralchenko, V.G.; Goovaerts, E.; Bertoni, G.; Van Tendeloo, G.; Konov, V.I. Hybrid Diamond-Graphite Nanowires Produced by Microwave Plasma Chemical Vapor Deposition. Adv. Mater. 2007, 19, 4058-4062. [CrossRef] 
18. Panda, K.; Sankaran, K.J.; Panigrahi, B.K.; Tai, N.-H.; Lin, I.N. Direct Observation and Mechanism for Enhanced Electron Emission in Hydrogen Plasma-Treated Diamond Nanowire Films. ACS Appl. Mater. Interfaces 2014, 6, 8531-8541. [CrossRef] [PubMed]

19. Hantschel, T.; Demeulemeester, C.; Eyben, P.; Schulz, V.; Richard, O.; Bender, H.; Vandervorst, W. Conductive diamond tips with sub-nanometer electrical resolution for characterization of nanoelectronics device structures. Phys. Status Solidi A 2009, 206, 2077-2081. [CrossRef]

20. Liao, M.; Hishita, S.; Watanabe, E.; Koizumi, S.; Koide, Y. Suspended Single-Crystal Diamond Nanowires for High-Performance Nanoelectromechanical Switches. Adv. Mater. 2010, 22, 5393-5397. [CrossRef] [PubMed]

21. Shellaiah, M.; Sun, K.W. A review on potential applications of diamond nanomaterials. Sci. Adv. Today 2016, 2, 25248 .

22. Arenal, R.; Bruno, P.; Miller, D.; Bleuel, M.; Lal, J.; Gruen, D. Diamond nanowires and the insulator-metal transition in ultrananocrystalline diamond films. Phys. Rev. B 2007, 75, 195431. [CrossRef]

23. Kholmanov, I.N.; Magnuson, C.W.; Aliev, A.E.; Li, H.; Zhang, B.; Suk, J.W.; Zhang, L.L.; Peng, E.; Mousavi, S.H.; Khanikaev, A.B.; et al. Improved Electrical Conductivity of Graphene Films Integrated with Metal Nanowires. Nano Lett. 2012, 12, 5679-5683. [CrossRef] [PubMed]

24. Osswald, S.; Yushin, G.; Mochalin, V.; Kucheyev, S.O.; Gogotsi, Y. Control of $\mathrm{sp}^{2} / \mathrm{sp}^{3}$ Carbon Ratio and Surface Chemistry of Nanodiamond Powders by Selective Oxidation in Air. J. Am. Chem. Soc. 2006, 128, 11635-11642. [CrossRef] [PubMed]

25. Hsu, C.-H.; Xu, J. Diamond nanowire-A challenge from extremes. Nanoscale 2012, 4, 5293-5299. [CrossRef] [PubMed]

26. Hsu, C.-H.; Cloutier, S.G.; Palefsky, S.; Xu, J. Synthesis of Diamond Nanowires Using Atmospheric-Pressure Chemical Vapor Deposition. Nano Lett. 2010, 10, 3272-3276. [CrossRef] [PubMed]

27. Zhang, J.; Zhu, Z.; Feng, Y.; Ishiwata, H.; Miyata, Y.; Kitaura, R.; Dahl, J.E.P.; Carlson, R.M.K.; Fokina, N.A.; Schreiner, P.R.; et al. Evidence of Diamond Nanowires Formed inside Carbon Nanotubes from Diamantane Dicarboxylic Acid. Angew. Chem. Int. Ed. 2013, 52, 3717-3721. [CrossRef] [PubMed]

28. Zhang, J.; Cao, J.X.; Chen, X.; Ding, J.W.; Zhang, P.; Ren, W. Diamond nanowires with nitrogen vacancy under a transverse electric field. Phys. Rev. B 2015, 91, 045417. [CrossRef]

29. Chang, L.-Y.; Ōsawa, E.; Barnard, A.S. Confirmation of the electrostatic self-assembly of nanodiamonds. Nanoscale 2011, 3, 958-962. [CrossRef] [PubMed]

30. Yoshikawa, T.; Reusch, M.; Zuerbig, V.; Cimalla, V.; Lee, K.-H.; Kurzyp, M.; Arnault, J.-C.; Nebel, C.; Ambacher, O.; Lebedev, V. Electrostatic Self-Assembly of Diamond Nanoparticles onto Al- and N-Polar Sputtered Aluminum Nitride Surfaces. Nanomaterials 2016, 6, 217. [CrossRef] [PubMed]

31. Hees, J.; Kriele, A.; Williams, O.A. Electrostatic self-assembly of diamond nanoparticles. Chem. Phys. Lett. 2011, 509, 12-15. [CrossRef]

32. Jang, D.M.; Im, H.S.; Back, S.H.; Park, K.; Lim, Y.R.; Jung, C.S.; Park, J.; Lee, M. Laser-induced graphitization of colloidal nanodiamonds for excellent oxygen reduction reaction. Phys. Chem. Chem. Phys. 2014, 16, 2411-2416. [CrossRef] [PubMed]

33. Li, L.-S.; Zhao, X. Dangling bond-induced graphitization process on the (111) surface of diamond nanoparticles. J. Chem. Phys. 2011, 134, 044711. [CrossRef] [PubMed]

34. Kononenko, V.V.; Gololobov, V.M.; Kononenko, T.V.; Konov, V.I. Photoinduced graphitization of diamond. Laser Phys. Lett. 2015, 12, 016101. [CrossRef]

35. Berman, D.; Deshmukh, S.A.; Narayanan, B.; Sankaranarayanan, S.K.R.S.; Yan, Z.; Balandin, A.A.; Zinovev, A.; Rosenmann, D.; Sumant, A.V. Metal-induced rapid transformation of diamond into single and multilayer graphene on wafer scale. Nat. Commun. 2016, 7, 12099. [CrossRef] [PubMed]

36. Shellaiah, M.; Chen, T.H.; Simon, T.; Li, L.-C.; Sun, K.W.; Ko, F.-H. An Affordable Wet Chemical Route to Grow Conducting Hybrid Graphite-Diamond Nanowires: Demonstration by A Single Nanowire Device. Sci. Rep. 2017, 7, 11243. [CrossRef] [PubMed]

37. Erdem, E.; Mass, V.; Gembus, A.; Schulz, A.; Liebau-Kunzmann, V.; Fasel, C.; Riedel, R.; Eichel, R.-A. Defect structure in lithium-doped polymer-derived $\mathrm{SiCN}$ ceramics characterized by Raman and electron paramagnetic resonance spectroscopy. Phys. Chem. Chem. Phys. 2009, 11, 5628-5633. [CrossRef] [PubMed]

38. Bateni, A.; Erdem, E.; Repp, S.; Acar, S.; Kokal, I.; Häßler, W.; Weber, S.; Somer, M. Electron paramagnetic resonance and Raman spectroscopy studies on carbon-doped MgB2 superconductor nanomaterials. J. Appl. Phys. 2015, 117, 153905. [CrossRef] 
39. García, J.M.; He, R.; Jiang, M.P.; Kim, P.; Pfeiffer, L.N.; Pinczuk, A. Multilayer graphene grown by precipitation upon cooling of nickel on diamond. Carbon 2011, 49, 1006-1012. [CrossRef]

40. Cooil, S.P.; Song, F.; Williams, G.T.; Roberts, O.R.; Langstaff, D.P.; Jørgensen, B.; Høydalsvik, K.; Breiby, D.W.; Wahlström, E.; Evans, D.A.; et al. Iron-mediated growth of epitaxial graphene on SiC and diamond. Carbon 2012, 50, 5099-5105. [CrossRef]

41. Shang, N.; Papakonstantinou, P.; Wang, P.; Zakharov, A.; Palnitkar, U.; Lin, I.N.; Chu, M.; Stamboulis, A. Self-Assembled Growth, Microstructure, and Field-Emission High-Performance of Ultrathin Diamond Nanorods. ACS Nano 2009, 3, 1032-1038. [CrossRef] [PubMed]

42. Shellaiah, M.; Simon, T.; Venkatesan, P.; Sun, K.W.; Ko, F.-H.; Wu, S.-P. Cysteamine-modified diamond nanoparticles applied in cellular imaging and $\mathrm{Hg}^{2+}$ ions detection. Appl. Surf. Sci. 2019, 465, 340-350. [CrossRef]

43. Ko, T.-Y.; Shellaiah, M.; Sun, K.W. Thermal and Thermoelectric Transport in Highly Resistive Single Sb2Se3 Nanowires and Nanowire Bundles. Sci. Rep. 2016, 6, 35086. [CrossRef] [PubMed]

44. Lee, Y.-J.; Jeng, K.-S.; Chen, J.-T.; Sun, K.W. Exceptionally low thermal conductivity of poly(3-hexylthiophene) single nanowires. RSC Adv. 2015, 5, 90847-90851. [CrossRef]

45. Reddy, K.M.; Padture, N.P.; Punnoose, A.; Hanna, C. Heterojunction metal-oxide-metal Au-Fe ${ }_{3} \mathrm{O}_{4}-\mathrm{Au}_{\text {single }}$ nanowire device for spintronics. J. Appl. Phys. 2015, 117, 17D710. [CrossRef]

46. Sankaran, K.J.; Lin, Y.-F.; Jian, W.-B.; Chen, H.-C.; Panda, K.; Sundaravel, B.; Dong, C.-L.; Tai, N.-H.; Lin, I.N. Structural and Electrical Properties of Conducting Diamond Nanowires. ACS Appl. Mater. Interfaces 2013, 5, 1294-1301. [CrossRef] [PubMed]

47. Shellaiah, M.; Simon, T.; Venkatesan, P.; Sun, K.W.; Ko, F.-H.; Wu, S.-P. Nanodiamonds conjugated to gold nanoparticles for colorimetric detection of clenbuterol and chromium(III) in urine. Microchim. Acta 2017, 185, 74. [CrossRef] [PubMed]

48. Szydlowski, J.; Van Hook, W.A. Concentration and Temperature Dependence of Dynamic Light Scattering for Some Polystyrene Solutions in Toluene, Cyclohexane, Methylcyclohexane and Deuteromethylcyclohexane. Macromolecules 1998, 31, 3266-3274. [CrossRef]

49. Filipe, V.; Hawe, A.; Jiskoot, W. Critical Evaluation of Nanoparticle Tracking Analysis (NTA) by NanoSight for the Measurement of Nanoparticles and Protein Aggregates. Pharm. Res. 2010, 27, 796-810. [CrossRef] [PubMed]

50. Németh, P.; Garvie, L.A.J.; Buseck, P.R. Twinning of cubic diamond explains reported nanodiamond polymorphs. Sci. Rep. 2015, 5, 18381. [CrossRef] [PubMed]

51. Morimoto, N.; Kubo, T.; Nishina, Y. Tailoring the Oxygen Content of Graphite and Reduced Graphene Oxide for Specific Applications. Sci. Rep. 2016, 6, 21715. [CrossRef] [PubMed]

52. Kharisov, B.I.; Kharissova, O.V.; Ortiz Méndez, U. Coordination and organometallic compounds as precursors of classic and less-common nanostructures: Recent advances. J. Coord. Chem. 2013, 66, 3791-3828. [CrossRef]

53. Zheng, J.; Wu, Y.; Deng, K.; He, M.; He, L.; Cao, J.; Zhang, X.; Liu, Y.; Li, S.; Tang, Z. Chirality-Discriminated Conductivity of Metal-Amino Acid Biocoordination Polymer Nanowires. ACS Nano 2016, 10, 8564-8570. [CrossRef] [PubMed]

54. Li, Q.; Jun, Y.-S. The apparent activation energy and pre-exponential kinetic factor for heterogeneous calcium carbonate nucleation on quartz. Commun. Chem. 2018, 1, 56. [CrossRef]

55. Stallinga, P. Electronic Transport in Organic Materials: Comparison of Band Theory with Percolation/(Variable Range) Hopping Theory. Adv. Mater. 2011, 23, 3356-3362. [CrossRef] [PubMed]

56. Xiong, S.; Ma, J.; Volz, S.; Dumitrică, T. Thermally-Active Screw Dislocations in Si Nanowires and Nanotubes. Small 2014, 10, 1756-1760. [CrossRef] [PubMed]

57. Matsumoto, T.; Kato, H.; Oyama, K.; Makino, T.; Ogura, M.; Takeuchi, D.; Inokuma, T.; Tokuda, N.; Yamasaki, S. Inversion channel diamond metal-oxide-semiconductor field-effect transistor with normally off characteristics. Sci. Rep. 2016, 6, 31585. [CrossRef] [PubMed]

58. Beloborodov, I.S.; Zapol, P.; Gruen, D.M.; Curtiss, L.A. Transport properties of n-type ultrananocrystalline diamond films. Phys. Rev. B 2006, 74, 235434. [CrossRef]

59. Trucchi, D.M.; Allegrini, P.; Bellucci, A.; Calvani, P.; Galbiati, A.; Girolami, M. Resistant and sensitive single-crystal diamond dosimeters for ionizing radiation. Nucl. Inst. Methods Phys. Res. A 2013, 718, 373-375. [CrossRef] 
60. Lions, M.; Saada, S.; Mazellier, J.-P.; Andrieu, F.; Faynot, O.; Bergonzo, P. Ultra-thin nanocrystalline diamond films (<100 nm) with high electrical resistivity. Phys. Status Solidi RRL 2009, 3, 205-207.

61. Ma, K.L.; Zhang, W.J.; Zou, Y.S.; Chong, Y.M.; Leung, K.M.; Bello, I.; Lee, S.T. Electrical properties of nitrogen incorporated nanocrystalline diamond films. Diamond Relat. Mater. 2006, 15, 626-630. [CrossRef]

62. Hsu, C.-H. Realization of New Form of Carbon-Diamond Nanowire-Synthesis, Sharacterization and Applications. Ph.D. Thesis, Brown University, Providence, RI, USA, 2011.

63. Ebbesen, T.W.; Lezec, H.J.; Hiura, H.; Bennett, J.W.; Ghaemi, H.F.; Thio, T. Electrical conductivity of individual carbon nanotubes. Nature 1996, 382, 54-56. [CrossRef]

64. Kiuchi, M.; Isono, Y.; Sugiyama, S.; Morita, T.; Matsui, S. Mechanical and electrical properties evaluation of carbon nanowire using electrostatic actuated nano tensile testing devices (EANAT). In Proceedings of the 5th IEEE Conference on Nanotechnology, Nagoya, Japan, 15 July 2005; Volume 2, pp. 486-489.

(C) 2019 by the authors. Licensee MDPI, Basel, Switzerland. This article is an open access article distributed under the terms and conditions of the Creative Commons Attribution (CC BY) license (http://creativecommons.org/licenses/by/4.0/). 